\title{
Predictors of support for biodiversity loss countermeasures and bushmeat consumption among Vietnamese urban residents
}

\author{
Minh-Hoang Nguyen 1,2,* \\ Thomas E. Jones ${ }^{1}$ \\ ${ }^{1}$ Graduate School of Asia Pacific Studies, Ritsumeikan Asia Pacific University, Beppu, Oita 874-8577, Japan \\ ${ }^{2}$ Centre for Interdisciplinary Social Research, Phenikaa University, Yen Nghia Ward, Ha Dong District, Hanoi \\ 100803, Vietnam \\ *Correspondence: ng19m6tk@apu.ac.jp (M.-H.N) \\ $* * * * *$
}

Abstract

Biodiversity loss is happening at an unprecedented rate, especially in countries like Vietnam with rich biodiversity and high population growth rate. One of the main causes of biodiversity loss in Vietnam is increasing bushmeat consumption in urban areas. To help mitigate the demand for bushmeat, this study aims to examine the associations between biodiversity loss perceptions, attitude towards the prohibition of illegal wildlife consumption, and bushmeat consumption behaviors among urban residents in Vietnam. The investigation employed the Bayesian Mindsponge Framework (BMF) on 535 respondents from multiple urban areas across Vietnam. We found that people perceiving environmental degradation, losses of economic growth, nature-based recreation opportunities, health, and knowledge as consequences of biodiversity loss were more likely to support the prohibition of illegal wildlife consumption. Although urban residents tended to consume bushmeat less frequently if they perceived losses of economic growth and knowledge as consequences of biodiversity loss, the perception of environmental degradation had an opposite effect on the behavior. Additionally, people consuming bushmeat frequently and supporting the biodiversity loss preventive measure seemed to share similar features: high income and educational levels. These paradoxical results hint at the existence of cultural additivity effects on psychology and behavior among Vietnamese urban residents. Given the influence of cultural additivity, It is recommended to put tougher measures (e.g. financial punishment) into perspective so that urban people can recognize the high "cost" of bushmeat consumption and change their attitude and behaviors accordingly. Apart from that, social marketing, demarketing, or educational campaigns should convey knowledge and information that can help receivers relate to their subjective cost-benefit judgements.

Keywords: wildlife consumption, biodiversity conservation, cultural additivity, Mindsponge mechanism, developing country

\section{Introduction}

Vietnam is a South-East Asian country that is located in the Indo-Burma region - one of the most biologically important and threatened hotspots worldwide. It has gained early global recognition for various unique and endemic species. In particular, Saola (Pseudoryx nghetinhensi) - the first large land vertebrate to be discovered over 50 years before 1992 - was documented in the forests near Vietnam's border with Laos [1]. However, the richness and endemism of species in Vietnam are under threat by many factors. Besides land conversion for agricultural use, infrastructure development, urbanization, invasive species, pollution, and climate change, the rising demand for wildlife products due to consumption in urban areas is also a main cause of biodiversity loss in Vietnam [2,3]. Thus, understanding urban residents' bushmeat consumption and attitude towards a preventive measure of biodiversity loss is necessary for preventing wildlife trafficking on the demand side. The current study aims to investigate the associations between biodiversity loss perceptions, attitude towards the prohibition of illegal wildlife consumption, and bushmeat consumption behavior among urban residents in Vietnam's largest cities.

Illegal wildlife trade prevention in Vietnam: supply-side and demand-side measures

The terrestrial ecosystems in Vietnam contain a great diversity of species that include more than 13,200 floral species and around 10,000 faunal species [4]. Nonetheless, biodiversity loss is happening at a critical rate. In the $2007 \mathrm{Vietnam}$ Red List, the number of threatened and endangered species increased by more than $20 \%$ to 882 species (418 animals 
and 464 plants), compared to the 1992-1996 Vietnam Red List [5]. Not to mention several species have gone extinct, like the flagship Javan rhinoceros (Rhinoceros sondaicus). The Javan rhino in Vietnam was declared to be locally extinct after the last one of its kind was found dead with its horn hacked off in Cat Tien National Park in 2010 [6]. Other species, like bears, pangolin, tigers, etc., also face the risk of extinction.

Illegal and excessive exploitation of biological resources is one of the main causes that directly drives the severe biodiversity degradation in Vietnam. Approximately 3,000 tons of wildlife and wildlife products are transferred in and out of Vietnam annually, with only a minimal proportion (3\%) was intercepted [7,8]. In 2010, over 34 tons of 13,000 wild animals were confiscated from illegal traders by the government [2]. Nguyen estimates that the total revenue of illegal wildlife trade in 2000 was $\$ 67$ million, 12 times higher than the total amount of legal wildlife trade (\$5.5 million) [9]. It is also calculated that half of the trade is for domestic consumption, mostly in urban areas [8]. Vietnam's persistent and even expanding illegal wildlife trading network derives mainly from the human-centred mindset towards the diverse ecosystem, historical consumption of wildlife, and inadequate environmental legislation system [8].

Since its participation in the Convention on Biological Diversity in 1994, Vietnam has undertaken actions to conserve biodiversity through implementing National Biodiversity Action Plans (NBAP). The latest NBAP, with strategic plans to 2020 and a vision to 2030, was approved by the Prime Minister in 2014. Effective conservation of wildlife and endangered, rare, and precious species is considered one of five key targets of the plan [2]. In addition to that, the Vietnamese government also enacted Decree 32/2006/ND-CP [10], Decree 82/2006/ND-CP [11], and Decree 35/2019/ND-CP [12], etc. for tackling supply-side activities in the illegal wildlife trade, such as poaching, harvesting, trading, transporting, and storing [13,14].

However, the supply-side measures, like enforcement and farmed wildmeat, are ineffective and insufficient to prevent illegal wildlife trade for several reasons. First, the wildlife protection policies are slowly and inadequately implemented and enforced. Second, resources for monitoring and law enforcement (e.g. manpower, finance, equipment) are insufficient. Third, the deficiency in the governmental system (e.g. corruption, bureaucracy) hinders protection efforts [9]. Fourth, the cooperation among agencies, organizations, and countries is lax [15]. Fifth, the socio-economic problem (e.g. crippling poverty) in source areas is still not resolved. Sixth, the illegal wildlife trading network has been more deliberately organized using social media to avoid enforcers' monitoring and inspection [16]. Seventh, poached wildmeat's low cost and socio-cultural values make it preferable to farmed substitutes $[17,18]$. Eighth, wildlife farming depends on wild populations for restocking, resulting in the laundering of illegal wildlife products [19].

Given these challenges, many scholars have suggested that additional demand-side measures should be considered and taken to curb poaching and illegal wildlife trading activities [15,20-22]. In Vietnam, residents of large urban centres, like Ho Chi Minh, Hanoi, Hai Phong, and Hue cities, have a high demand for bushmeat consumption due to socio-cultural motives $[13,20,23]$. Therefore, social marketing and demarketing campaigns in urban areas are essential to reduce or shift the demand from this commodity to other more sustainable options [15,24]. During the COVID-19 pandemic, the government has implemented Directive No. 29/CT-TTg to consolidate law enforcement of illegal wildlife trade for the sake of public health [25]. Besides strengthening supply-side measures, the Directive also prohibits illegal wildlife consumption among all citizens, especially governmental officers and their relatives. Understanding the predictors of urban residents' wildlife consumption behaviors and support for wildlife consumption prohibition might help improve the effectiveness of social marketing, demarketing, and law enforcement endeavors.

Wildlife consumption perceptions and behaviors among urban residents

Multiple anthropological factors cause biodiversity loss. Thus, scientists have long believed that a better understanding of the interactions between humans and environmental issues will improve conservation policies, actions and outcomes by making them more legitimate, salient, robust and effective. Studies on these interactions can be called conservation social sciences. Bennett, et al. [26] classify them into 18 disciplines, though many might be overlapping. Among these disciplines, environmental and conservation psychology focuses on humans' thoughts and behaviors regarding natural and conservation-related topics. Having insights into the individuals' thoughts and behaviors towards a particular conservation initiative, management action, consumption behavior can help enhance the effectiveness of marketing campaigns, management strategies, and policymaking [27]. 
Several studies have been conducted to explore the behaviors of wildmeat consumption and their underlying motives among Vietnamese urban residents. More specifically, a majority of reported wildmeat consumption cases take place in restaurant settings $[13,20,28]$. The profiles of bushmeat consumers are heterogeneous. Drury [20] suggests that successful, high-income, high-status male residents are more likely to eat bushmeat to convey wealth and social status. In contrast, Olmedo, Veríssimo, Challender, Dao and Milner-Gulland [23] indicate that there are three major groups of bushmeat consumers: 1) classic consumers (older, less educated), 2) up-and-coming professionals (younger, wealthier, more educated), 3) and students. Among these groups, students have limited influence on the food choice in certain social contexts and are less likely to consume wildmeat than classic consumers and up-and-coming professionals. Even though the most frequently consumed wildmeat is wild pig (Sus Scrofa - least concerned species in the IUCN red list), many species listed as 'endangered' and 'critically endangered' in the red list are also eaten, such as pangolins (Manis spp.), Vietnamese box turtles (Cuora galbinifrons), civets (Viverra zibetha or Viverricula indica) $[13,20,28]$.

Scientists have shown that the key motives of bushmeat consumption behaviors among urban Vietnamese are their underlying socio-cultural values. High-income, high-status residents intentionally select rarer, wild-sourced, and more expensive wildmeats for achieving social benefits, such as securing business or gaining social advantage $[13,20]$. Confucianism is deep-rooted in Vietnamese beliefs and behaviors [29], so serving others with rare wildmeats will help display social status and prestige. Speaking in an indigenous language, it makes and keeps people's "face" [30]. Apart from being a medium to communicate prestige and social leverage, associating bushmeat with quality, nutritional value, health benefits, and taste is also a significant motive that influences bushmeat consumption [28]. The Vietnamese cultural values might shape such perceptions through generations (e.g. traditional medicinal philosophy) $[13,31]$.

It has been found that increased environmental knowledge can positively affect environmental attitudes, proenvironmental behavioral intentions and behaviors [32-36]. Therefore, if urban residents perceive the adverse consequences of biodiversity loss, their attitude towards preventive measures of biodiversity loss and bushmeat consumption behaviors are expected to change. However, little is known about the associations between urban people's biodiversity loss perceptions, attitude towards biodiversity loss preventive measure, and bushmeat consumption behavior among urban residents. Thus, the current study attempts to answer the following two research questions:

1) How are Vietnamese urban residents' perceived consequences of biodiversity loss associated with the support for the prohibition of illegal wildlife consumption?

2) How are Vietnamese urban residents' perceived consequences of biodiversity loss associated with the frequency of their bushmeat consumption?

\section{Method and Materials}

\subsection{Data collection}

We performed the research using a dataset of 535 Vietnamese urban residents [37]. The dataset was collected through a web-based survey via Google Forms using a snowball sampling strategy in multiple cities in Vietnam, from $18^{\text {th }}$ June to $8^{\text {th }}$ August 2021. A web-based survey was performed because the Vietnamese government was implementing strict social distancing due to the Covid-19 outbreak at that time. Before the survey collection, in-depth interviews were performed with 38 urban residents in Vietnam's two largest cities (Ho Chi Minh and Hanoi) for designing the questionnaire because little was known about biodiversity perceptions among Vietnamese urban residents. Before responding to the survey, participants were required to read and agree to the consent form that carefully explained all the research purposes, contents, and confidentiality rights. As an incentive, we also provided a gift card with the value ranging from $\$ 1$ to $\$ 10$ to two hundred randomly-selected participants via their email addresses.

One weak point of online survey collection is that we could not control who would respond to the questionnaire. Some people responded multiple times for acquiring gift cards, while some participants were deemed ineligible. Thus, after retrieving the data, we performed a four-step quality check to exclude unqualified samples. First of all, we removed 
respondents that were not residing in urban areas based on their reported residency. Next, participants less than 18year-old were also excluded because their responses were deemed not legitimate without guardians' acceptance. After that, we removed all duplicate responses based on the reported email addresses. Finally, any respondents replying to a set of questions using the same answer and selecting all answers of checkbox questions simultaneously were excluded. These behaviors are 'straightlining' and 'select-all' answers, which can lead to unreliable findings [38]. As a result, from 581 acquired responses, 46 data lines were removed, and only 535 samples were included in the later analysis.

\subsection{Variables}

In order to examine the associations between urban residents' perceptions about biodiversity loss, bushmeat consumption behaviors, and attitude towards the prohibition of illegal wildlife consumption, we employed 11 variables in the Bayesian analysis (two outcome variables and nine predictor variables). WildConsProhibi is the outcome variable demonstrating the attitude towards the prohibition of illegal wildlife consumption, while Bushmeat is the outcome variable representing the bushmeat consumption frequency.

Nine predictor variables could be classified into two types: 1) demographic features and 2) perceptions about biodiversity loss's impacts (see Table 1). Variables of demographic features included Sex, Education, and Income. Initially, there were ten variables regarding the perceptions about biodiversity loss, but some of them were relatively similar, so we grouped them into five variables based on their characteristics to avoid multicollinearity and model redundancy. Specifically, perceived pollution and climate change as consequences of biodiversity loss were grouped into EnvironmentalDegradation, with 0.88 of Cronbach alpha; perceived loss of green space, natural aesthetics, and nature-based recreation were grouped into NatureRecreationLoss, with 0.85 of Cronbach alpha; perceived reduction of physical health, mental health, and life expectancy were grouped into HealthLoss, with 0.92 of Cronbach alpha. All the Cronbach alphas were higher than 0.8 and 0.9 , suggesting that these groups had good and excellent internal reliabilities $[39,40]$.

Table 1: Description of variables

\begin{tabular}{|c|c|c|c|}
\hline Variable & Meaning & $\begin{array}{c}\text { Type of } \\
\text { variable }\end{array}$ & Value \\
\hline WildConsProhibi & $\begin{array}{l}\text { Whether the respondent } \\
\text { supports the prohibition of } \\
\text { illegal wildlife consumption is a } \\
\text { preventive measure of } \\
\text { biodiversity loss }\end{array}$ & Binary & $\begin{array}{c}\text { Agree }=1 \\
\text { Disagree }=0\end{array}$ \\
\hline Bushmeat & $\begin{array}{c}\text { Frequency of consuming } \\
\text { bushmeat }\end{array}$ & Numerical & $\begin{array}{c}\text { Never }=1 \\
\text { Sometimes }=2 \\
\text { Often }=3 \\
\text { Very often }=4\end{array}$ \\
\hline $\operatorname{Sex}$ & Biological sex & Binary & $\begin{array}{c}\text { Male }=1 \\
\text { Female }=0\end{array}$ \\
\hline Education & Highest educational level & Numerical & $\begin{array}{c}\text { Primary school }=1 \\
\text { Secondary school }=2 \\
\text { High school }=3 \\
\text { Undergraduate }=4 \\
\text { Post-graduate }=5\end{array}$ \\
\hline Income & Income level & Numerical & $\begin{array}{c}\text { No income }=1 \\
\text { Less than } 5 \text { million VND }= \\
2 \\
5-10 \text { million VND }=3 \\
10-15 \text { million VND }=4 \\
15-20 \text { million VND }=5 \\
20-30 \text { million VND }=6 \\
\text { More than } 30 \text { million VND } \\
=7\end{array}$ \\
\hline
\end{tabular}




\begin{tabular}{|c|c|c|c|}
\hline EnvironmentalDegradation & $\begin{array}{c}\text { Whether the respondent } \\
\text { perceives environmental } \\
\text { degradation (pollution and } \\
\text { climate change) as a } \\
\text { consequence of biodiversity loss }\end{array}$ & Numerical & $\begin{array}{l}\text { Ranging from } 1 \text { (strongly } \\
\text { disagree) to } 4 \text { (strongly } \\
\text { agree) }\end{array}$ \\
\hline EconomicGrowthLoss & $\begin{array}{l}\text { Whether the respondent } \\
\text { perceives the loss of economic } \\
\text { growth as a consequence of } \\
\text { biodiversity loss }\end{array}$ & Numerical & $\begin{array}{c}\text { Ranging from } 1 \text { (strongly } \\
\text { disagree) to } 4 \text { (strongly } \\
\text { agree) }\end{array}$ \\
\hline NatureRecreationLoss & $\begin{array}{c}\text { Whether the respondent } \\
\text { perceives the loss of nature- } \\
\text { based recreation (loss of green } \\
\text { space, natural aesthetics, nature- } \\
\text { based recreation) as a } \\
\text { consequence of biodiversity loss }\end{array}$ & Numerical & $\begin{array}{c}\text { Ranging from } 1 \text { (strongly } \\
\text { disagree) to } 4 \text { (strongly } \\
\text { agree) }\end{array}$ \\
\hline HealthLoss & $\begin{array}{l}\text { Whether the respondent } \\
\text { perceives the loss of health } \\
\text { (reduction of physical health, } \\
\text { mental health, and life } \\
\text { expectancy) as a consequence of } \\
\text { biodiversity loss }\end{array}$ & Numerical & $\begin{array}{c}\text { Ranging from } 1 \text { (strongly } \\
\text { disagree) to } 4 \text { (strongly } \\
\text { agree) }\end{array}$ \\
\hline KnowledgeLoss & $\begin{array}{c}\text { Whether the respondent } \\
\text { perceives the loss of knowledge } \\
\text { as a consequence of biodiversity } \\
\text { loss }\end{array}$ & Numerical & $\begin{array}{c}\text { Ranging from } 1 \text { (strongly } \\
\text { disagree) to } 4 \text { (strongly } \\
\text { agree) }\end{array}$ \\
\hline
\end{tabular}

\subsection{Model construction}

Bayesian Mindsponge Framework (BMF), also known as the Bayesian Mindsponge analytical approach, was employed to construct and analyze the model. BMF, first utilized by Nguyen, et al. [41] to examine the suicidal ideation mechanism, is an approach that uses the Mindsponge mechanism as a theoretical framework and Bayesian statistics as an analytical tool to investigate psychological and behavioral issues.

Mindsponge mechanism, which explains how an individual absorbs and eject cultural values into and out of the mind, indicates that the information absorption process is conditional on the information existing in the mindset and external environment $[42,43]$. To elaborate, when an individual acquires information, the information will need to go through the multi-filtering process that combines and evaluates the new information with existing information. The process leads to three outcomes: 1) the information is allowed to approach closer to the mindset if it is considered beneficial; 2) the information is pushed out if it is considered costly; 3) the information is stored in the buffer zone for later deliberation if it is considered neither beneficial nor costly. The closer to the mindset the information is, the stricter the cost-benefit evaluation filter it has to face.

Based on the cost-benefit judgement process of an individual, we assumed that individuals perceiving more negative impacts inflicted by biodiversity loss are more likely to accept the ideation of prohibiting illegal wildlife consumption and consume bushmeat less frequently. To elaborate, if an individual knows that biodiversity loss can adversely affect their life (e.g. living environment quality, health, etc.) or what brings them benefit (e.g. nature-based recreation, economic growth, knowledge, etc.), they will be more likely to accept ideation of biodiversity loss preventive measure to come close to their mindset [44]. This acceptance will eventually influence their thoughts and behaviors.

Besides the perceptions of biodiversity loss's impacts, demographic factors were also added to the two models for identifying urban people groups that are more likely to support the prohibition of illegal wildlife consumption and consume bushmeat more frequently. These insights would be valuable for policymaking recommendations. As a result, Models 1 and 2 are presented as follows: 


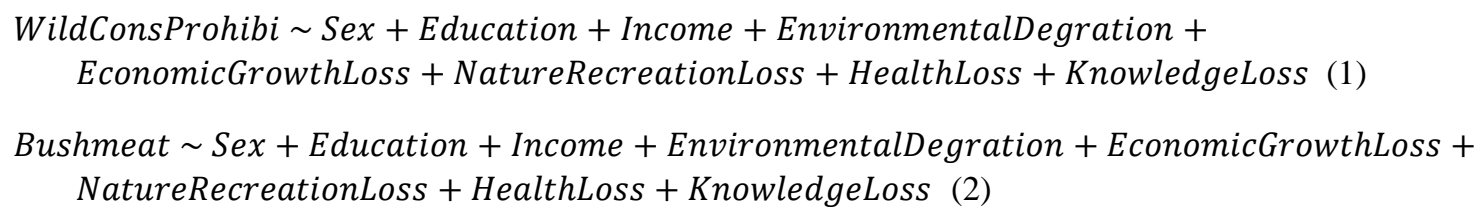

2.4. Model analysis and validation

Bayesian analysis was incorporated with the Mindsponge mechanism and employed in the current study for three main reasons. First, in psychological research, associations among psychological and behavioral factors might be influenced by various underlying factors and mechanisms. Bayesian inference treats all parameters probabilistically, including uncertainties, so it helps quantify these uncertainties under probability distributions $[45,46]$. Second, Bayesian inference is conditional on what is known and not constrained by asymptotic theory and skewed data; in other words, it provides exact inference on the data at hand [47,48]. Particularly, based on the probability distributions of parameters, we can find the exact probability that the associations between perceptions about biodiversity loss and attitude towards prohibition measure occur [47]. As the current dataset was not collected using a random sampling strategy, acquiring exact inference from the current dataset will also facilitate later replicative studies or comparison with inferred results using a better sampling dataset.

Incorporating prior information into the model can provide a useful supplement to the analysis when the data are weak [49,50]. Among predictor variables, the perceptions about biodiversity loss's impacts tend to be highly correlated, resulting in multicollinearity. Multicollinearity is a weak data identification problem associated with large standard errors of estimated parameters [51], so it can be alleviated by utilizing informative priors for the given parameters $[52,53]$.

Selecting the right priors is very important, requiring a strong theoretical foundation to support the belief. Based on the Mindsponge mechanism, we believed that perceptions about biodiversity loss might positively influence the attitude towards the prohibition of illegal wildlife consumption and negatively influence the bushmeat consumption frequency. Thus, their parameters' prior distributions in Model 1 were set as normal distributions with 1 as mean and 0.5 as standard deviation. In contrast, theirs in Model 2 were set as normal distributions with -1 as mean and 0.5 as standard deviation because we believed perceptions about biodiversity loss might negatively affect the bushmeat consumption frequency.

Nevertheless, employing prior distributions in the estimation might lead to subjective bias. Thus, we performed the "prior-tweaking" technique to check the results' sensitivity if the prior distributions were adjusted [54]. In detail, we reran the estimations of Model 1 and 2 using prior distributions set as normal distributions with 0 as mean and 0.5 as standard deviation. If the new posterior results are not sensitive to adjusted prior beliefs, they can be deemed robust and not subjectively biased.

In order to validate our models' robustness, a three-step validation strategy was adopted. First, Pareto smoothed importance-sampling leave-one-out cross-validation (PSIS-LOO) was employed to check the model's goodness-offit [55]. The model's goodness-of-fit can be classified into four levels: 1) 'good' if its $k$-values are all below $0.5,2$ ) 'OK' if its $k$-values are more than 0.5 and below $0.7,3$ ) 'bad' if its $k$-values are more than 0.7 and below 1 , and 4) 'very bad' if its $k$-values are more than 1 . Next, we checked the Markov chain central limit theorem using two diagnostic statistics: effective sample size (n_eff) and Gelman shrink value (Rhat). If the n_eff values are larger than 1,000 and the Rhat values equal 1, they will imply the good convergence of parameters' Markov chains. The Markov chains' convergence was also validated visually using trace plots, Gelman plots, and autocorrelation plots. "Priortweaking technique" was the third validation step.

All the analyses were conducted using the bayesvl R package due to its user-friendly operation method, capacity to visualize eye-catching graphics, and cost-effectiveness [56-58]. The models were fitted with four Markov chains. Each chain includes 5,000 iterations, of which the first 2,000 were set as warmup iterations. 
3. Results

Overall, female respondents constituted more than half of the samples (57.08\%). The mean age reported was around 33-year-old, and their average income was approximately 13,700,000 VND per month. 95.51\% of the respondents agreed with the prohibition of illegal wildlife consumption. Regarding bushmeat consumption frequency, most urban residents reported having never consumed bushmeat $(64.49 \%)$, while only $0.37 \%$ consumed bushmeat often and very often.

\subsection{Model 1}

In this subsection, we present the simulated results of Model 1, which was constructed to explore how urban residents' perceptions about biodiversity loss and demographic features predict their attitude towards the prohibition of illegal wildlife consumption. Model 1's logical network is shown in Figure 2.

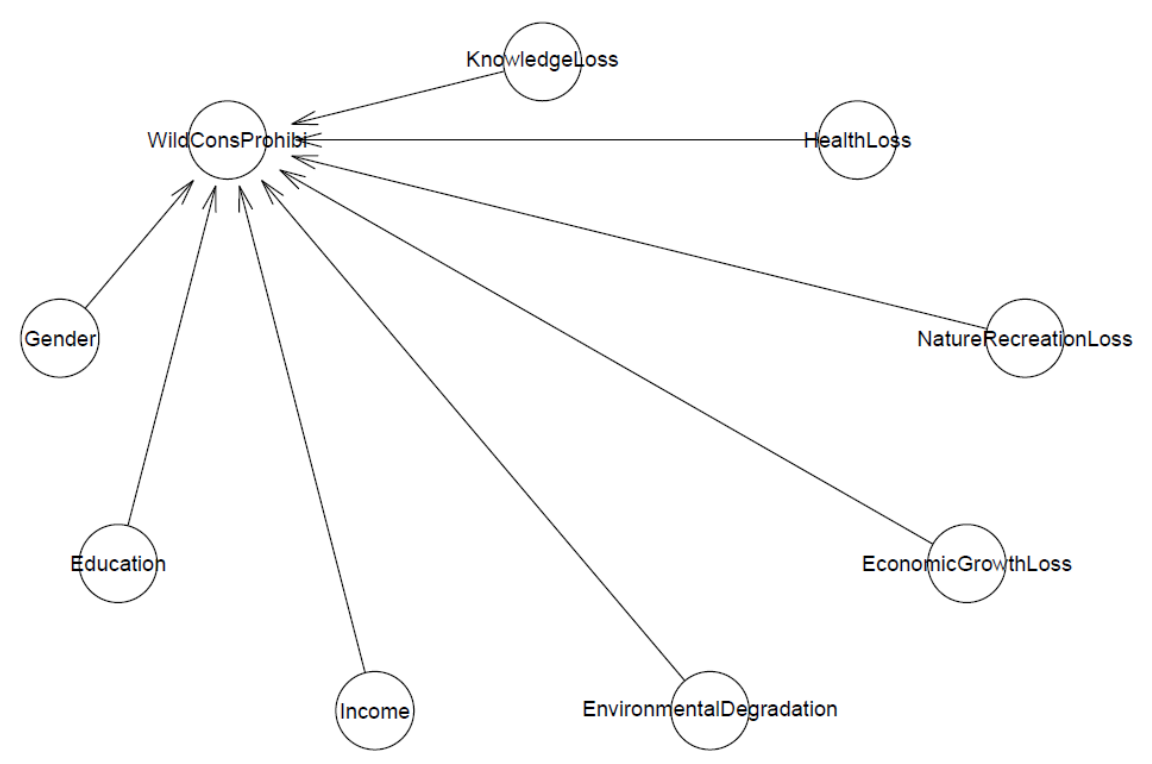

Figure 2: Model 1's logical network

According to the PSIS-LOO test, Model 1's goodness-of-fit can be considered 'good' as all its $k$-values are located below the threshold of 0.5 (see Figure 3). 


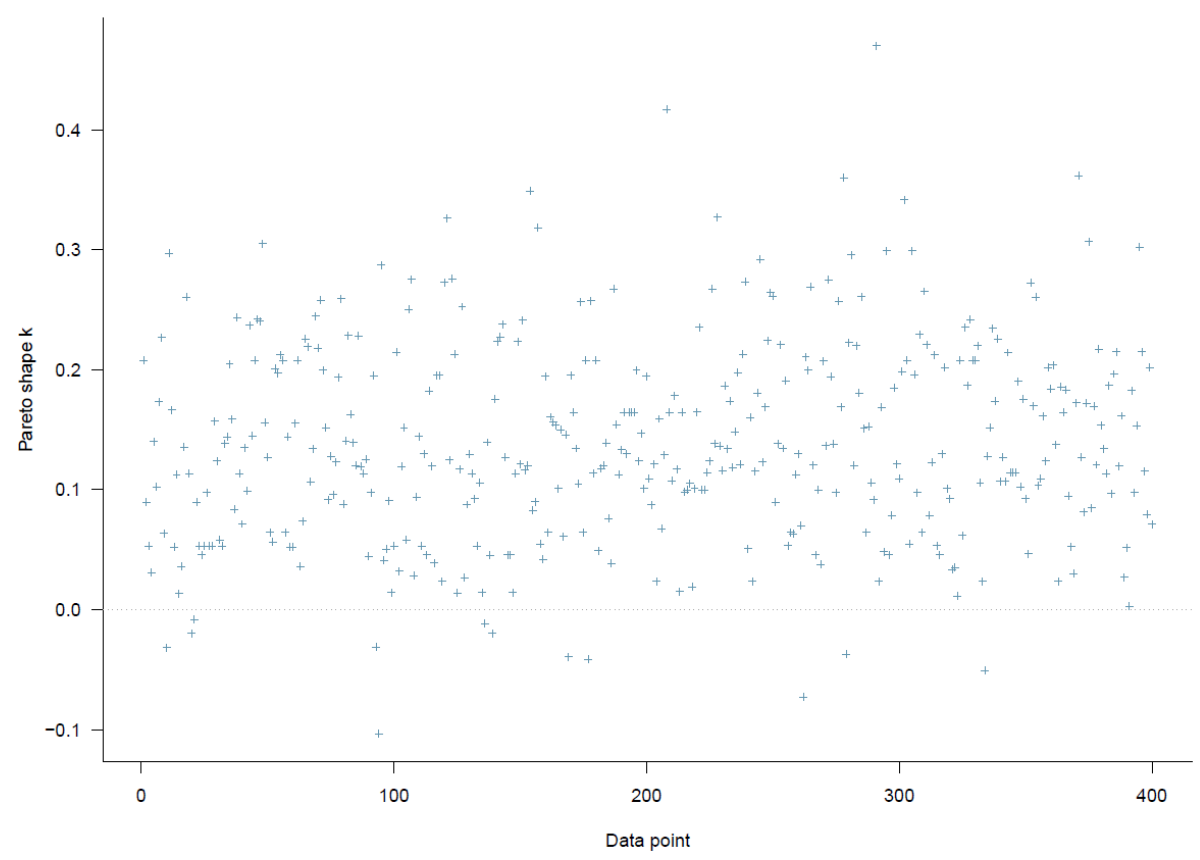

Figure 3: PSIS diagnostic plot of Model 1 with informative prior being normal distribution $(1,0.5)$

Then, we checked whether the Markov chain central limit theorem is held after fitting Model 1. The n_eff and Rhat statistics of Model 1 indicate good signals of convergence, regardless of informative priors. In particular, all n_eff statistics are larger than 1,000, and all Rhat statistics are equal to 1 (see Table 2). Visually, the trace plots shown in Figure 4 demonstrate good convergence of Markov chains, or "healthy" stochastic simulation processes, which are stationary and centralized. In the Gelman plots, the shrink factors drop rapidly to 1 before the warmup period ends (before the 2,000 ${ }^{\text {th }}$ iteration). At the same time, the parameters' autocorrelation levels decline swiftly to 0 after a certain number of lags (well below 5). These signals are also firm evidence that the Markov chain central limit theorem is held when fitting Model 1. 

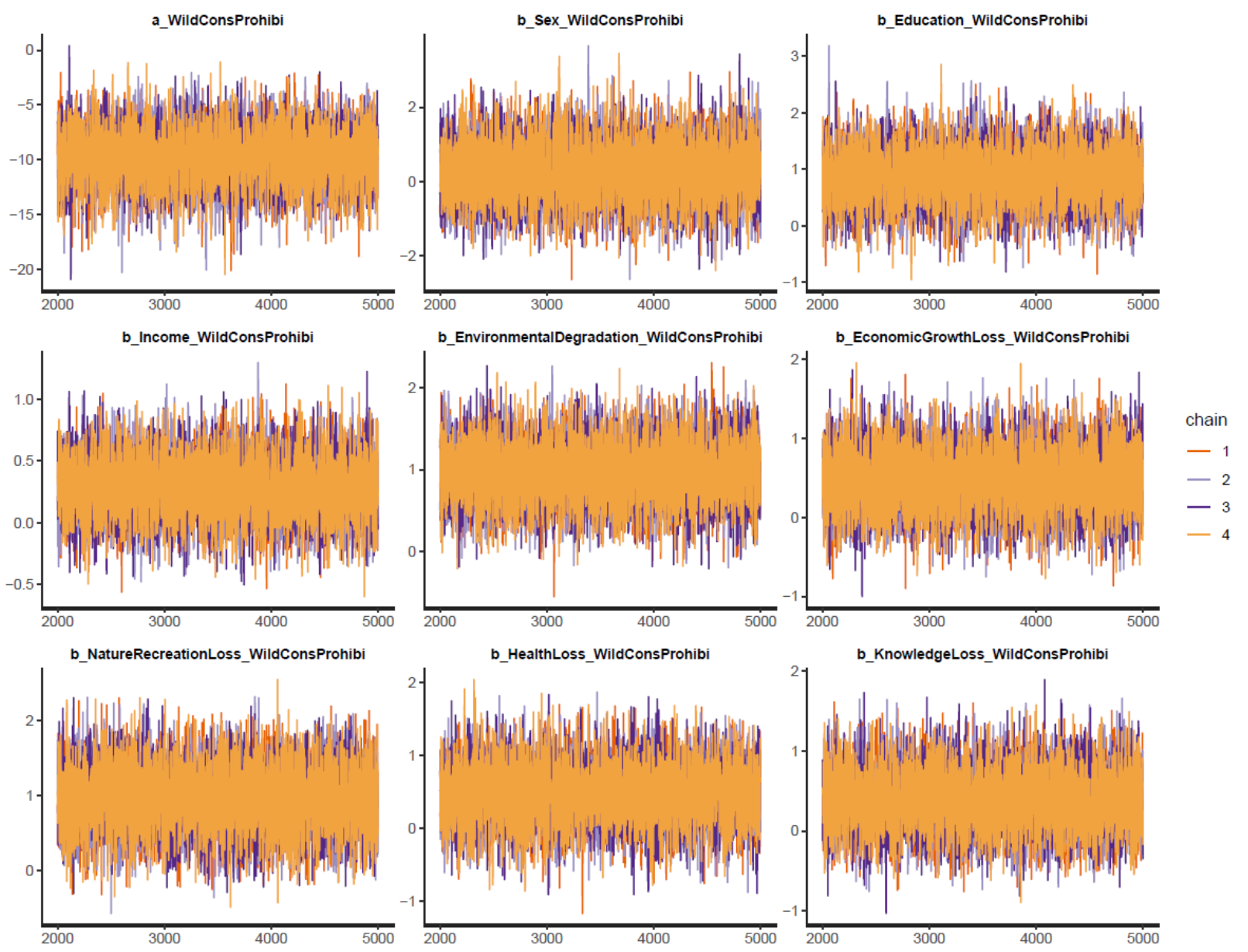

Figure 4: Model 1's trace plots with informative prior being normal distribution $(1,0.5)$

When fitting Model 1 using informative priors implying our belief on the effects of biodiversity loss perceptions on the attitude towards the prohibition of illegal wildlife consumption, we find that all five perceptions are positively associated with the attitude. In other words, urban residents who think that biodiversity loss causes environmental degradation, loss of economic growth, loss of nature-based recreation opportunities, loss of health, and loss of knowledge are more likely to agree with the measure prohibiting illegal wildlife consumption (see Table 2). Among five perceived adverse impacts, EnvironmentalDegradation $\left(\mu_{\text {EnvironmentalDegradation }}=0.96\right.$ and $\left.\sigma_{\text {EnvironmentalDegradation }}=0.36\right)$ and NatureRecreationLoss $\left(\mu_{\text {NatureRecreationLoss }}=0.96\right.$ and $\sigma_{\text {NatureRecreationLoss }}$ $=0.42$ ) are two perceptions that have the greatest effect on the urban residents' attitude.

The simulated results using informative priors implying our disbelief, all five biodiversity loss perceptions still exhibit positive impacts on the biodiversity prevention attitude, so Model 1's results can be deemed robust. However, some effects are less reliable. Specifically, most of the probability distributions of parameters about biodiversity loss perceptions in Figure 5A are located mostly on the right side of the red vertical line (at 0), indicating reliable positive effects. However, although most of the probability distributions of EconomicGrowth and HealthLoss lie on the right, they still have some probabilities of negatively affecting the biodiversity prevention attitude (see Figure 5B).

Regarding the demographic factors, it is found that the highest level of education $\left(\mu_{\text {Education }}=0.88\right.$ and $\sigma_{\text {Education }}=$ $0.47)$ and level of income $\left(\mu_{\text {Education }}=0.28\right.$ and $\left.\sigma_{\text {Education }}=0.24\right)$ are both positively associated with the prevention attitude, but there is no clear impact of respondent's sex on the attitude $\left(\mu_{\text {Sex }}=0.26\right.$ and $\left.\sigma_{\text {Sex }}=0.77\right)$. The effect of Income is relatively reliable as a certain part of its probability distribution is still located on the negative side in Figure 
5B (left side of the red vertical line). In contrast, most of Education's probability lies on the positive side, regardless of informative priors, suggesting the high reliability of the association.

Table 2: Model 1's simulated posterior results

\begin{tabular}{|c|c|c|c|c|c|c|c|c|}
\hline \multirow{2}{*}{ Parameters } & \multicolumn{3}{|c|}{$\begin{array}{c}\text { Informative priors } \\
\text { (belief on effect) }\end{array}$} & \multicolumn{4}{c|}{$\begin{array}{c}\text { Informative priors } \\
\text { (disbelief on effect) }\end{array}$} \\
\cline { 2 - 10 } & Mean & SD & n_eff & Rhat & Mean & SD & n_eff & Rhat \\
\hline Constant & -9.77 & 2.48 & 7461 & 1 & -6.92 & 2.14 & 7465 & 1 \\
\hline EnvironmentalDegradation & 0.96 & 0.36 & 10152 & 1 & 0.79 & 0.34 & 10021 & 1 \\
\hline EconomicGrowthLoss & 0.48 & 0.38 & 10264 & 1 & 0.25 & 0.36 & 10612 & 1 \\
\hline NatureRecreationLoss & 0.96 & 0.42 & 10132 & 1 & 0.79 & 0.41 & 10622 & 1 \\
\hline HealthLoss & 0.47 & 0.40 & 10842 & 1 & 0.26 & 0.39 & 11785 & 1 \\
\hline KnowledgeLoss & 0.40 & 0.37 & 10963 & 1 & 0.33 & 0.35 & 10732 & 1 \\
\hline Gender & 0.26 & 0.77 & 10457 & 1 & 0.29 & 0.68 & 12622 & 1 \\
\hline Education & 0.88 & 0.47 & 8978 & 1 & 0.72 & 0.42 & 8112 & 1 \\
\hline Income & 0.28 & 0.24 & 9987 & 1 & 0.19 & 0.22 & 10531 & 1 \\
\hline
\end{tabular}

A

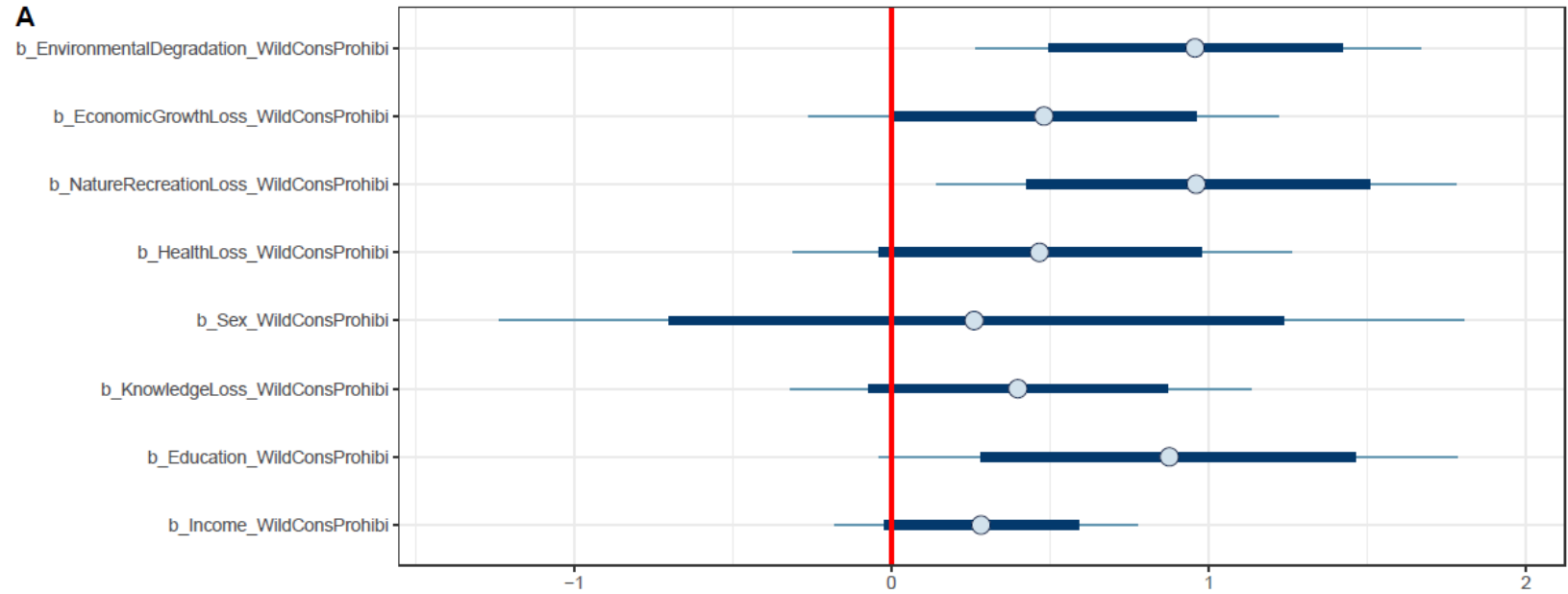

B

b_EnvironmentalDegradation_WildConsProhib

b_EconomicGrowthLoss_WildConsProhibi

b_NatureRecreationLoss_WildConsProhibi -

b_HealthLoss_WildConsProhibi -

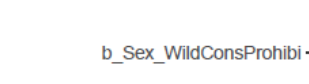

b_KnowledgeLoss_WildConsProhibi

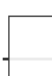

$-1$

b_Education_WildConsProhibi

b_Income_WildConsProhibi -

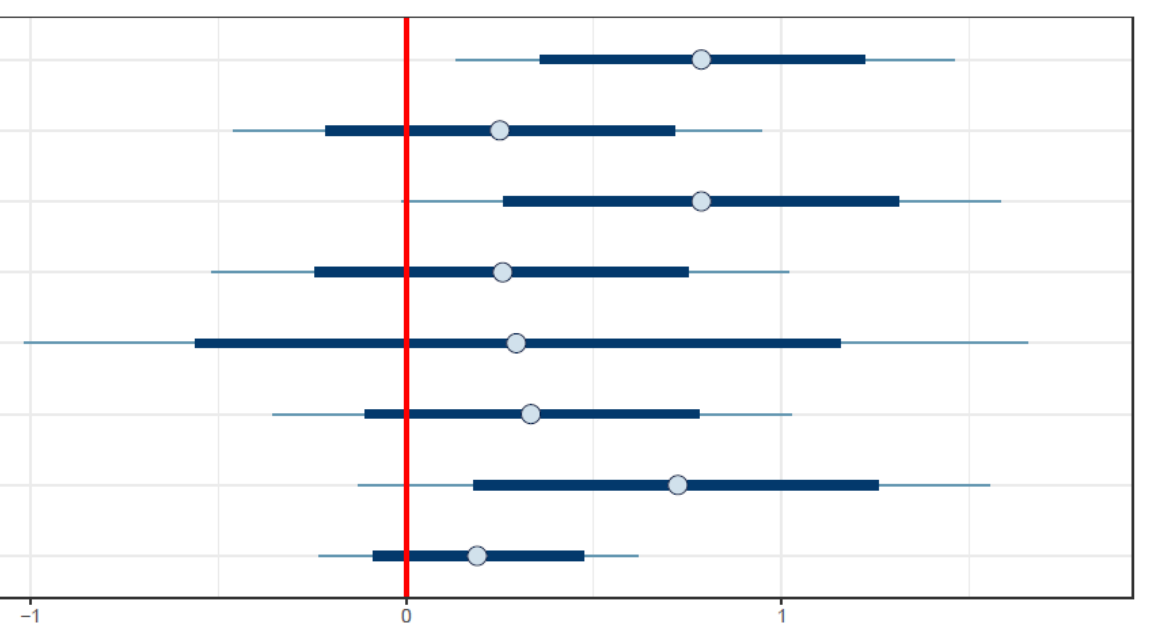

Figure 5: Model 1's interval plots of parameters' probability distributions. A - with informative prior being normal distribution $(1,0.5), \mathbf{B}$ - with informative prior being normal distribution $(0,0.5)$ 


\subsection{Model 2}

In the second model, we aim to investigate how urban residents' perceptions about biodiversity loss impacts and demographic features predict their bushmeat consumption behaviors. The logical network of Model 2 is illustrated in Figure 6.

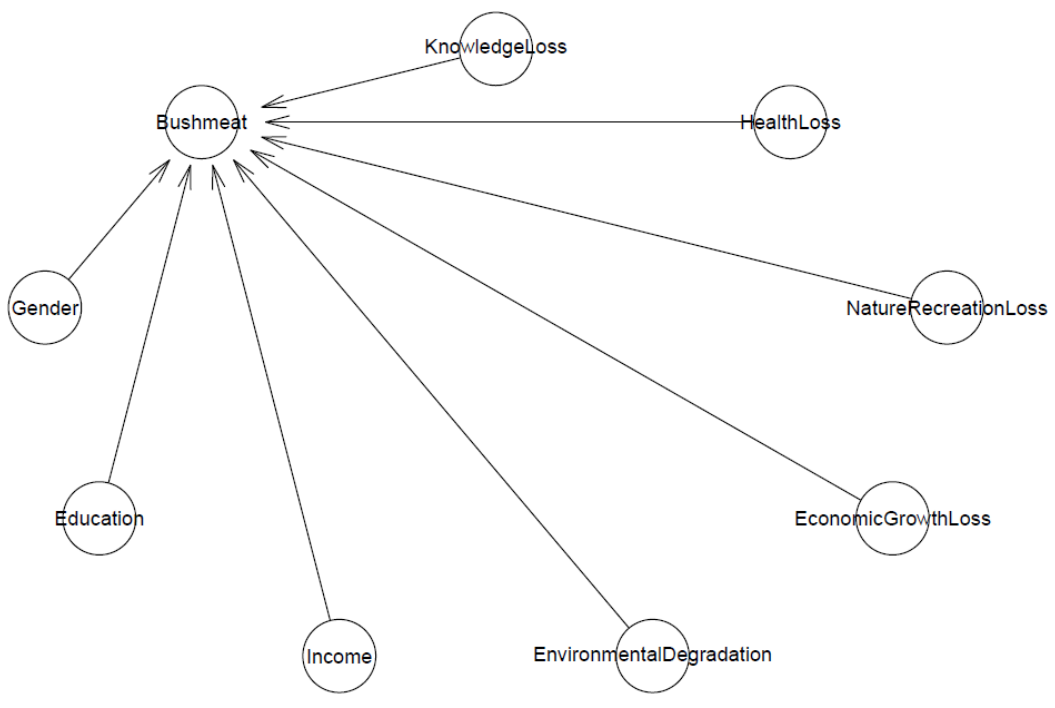

Figure 6: Model 2's logical network

Model 2's goodness-of-fit with the data is generally good because $k$-values are well below the 0.5 threshold.

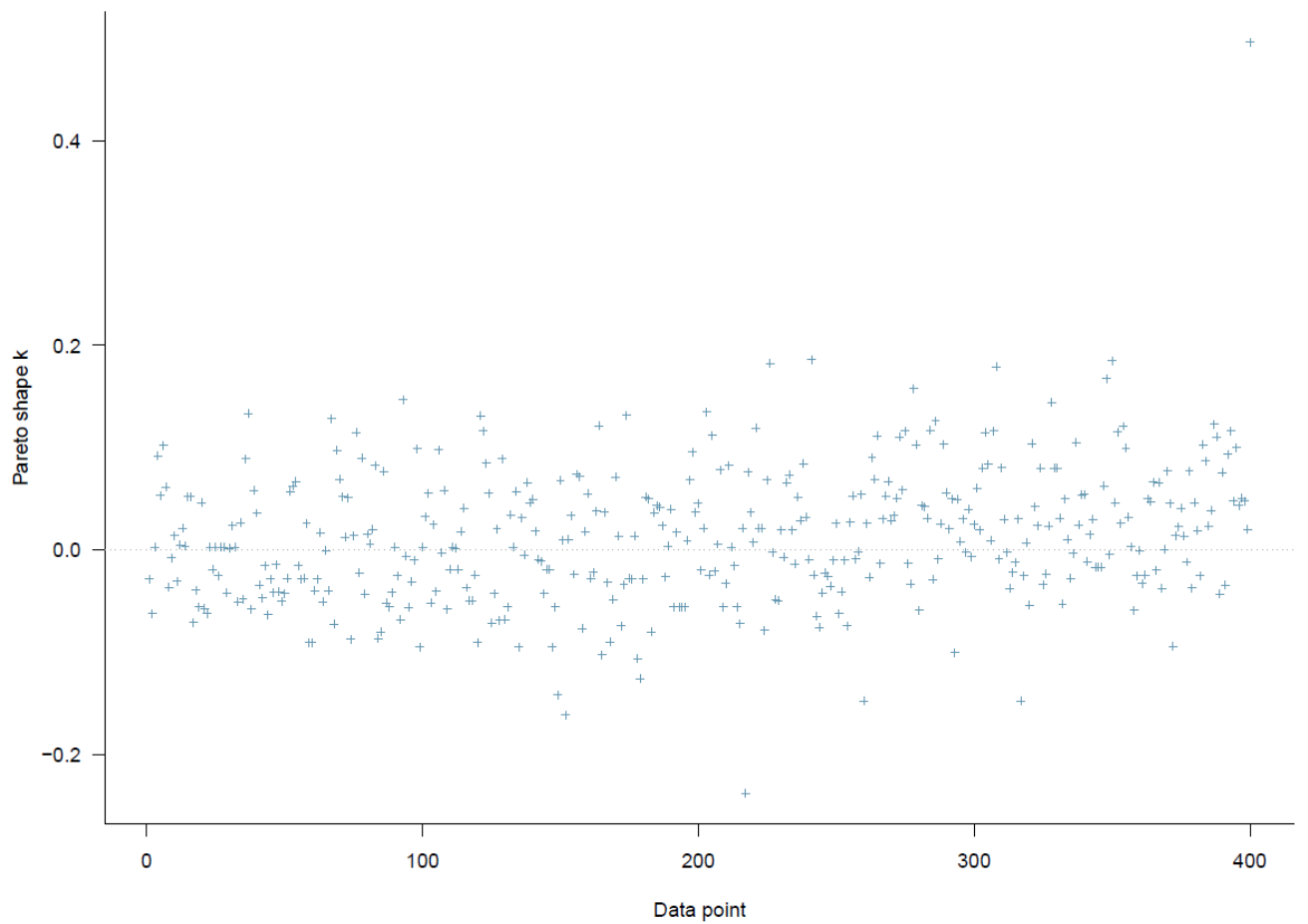

Figure 7: PSIS diagnostic plot of Model 2 with informative prior being normal distribution $(-1,0.5)$ 
The Markov chain convergence in Model 2 can be examined using the effective sample size and Gelman factor displayed in Table 3. As can be observed that in both simulations using informative priors implying belief or disbelief in the effect, all the n_eff statistics are beyond 1,000, while all Rhat statistics are equal to 1 . These statistics hint at the good convergence of Markov chains during the stochastic simulation process. The healthy convergence of Markov chains is clearly visualized using trace plots in Figure 8. The rapid decline of shrink factors and autocorrelation levels in Figure S3 and S4, respectively, also validate that the Markov central limit theorem is held in Model 2.
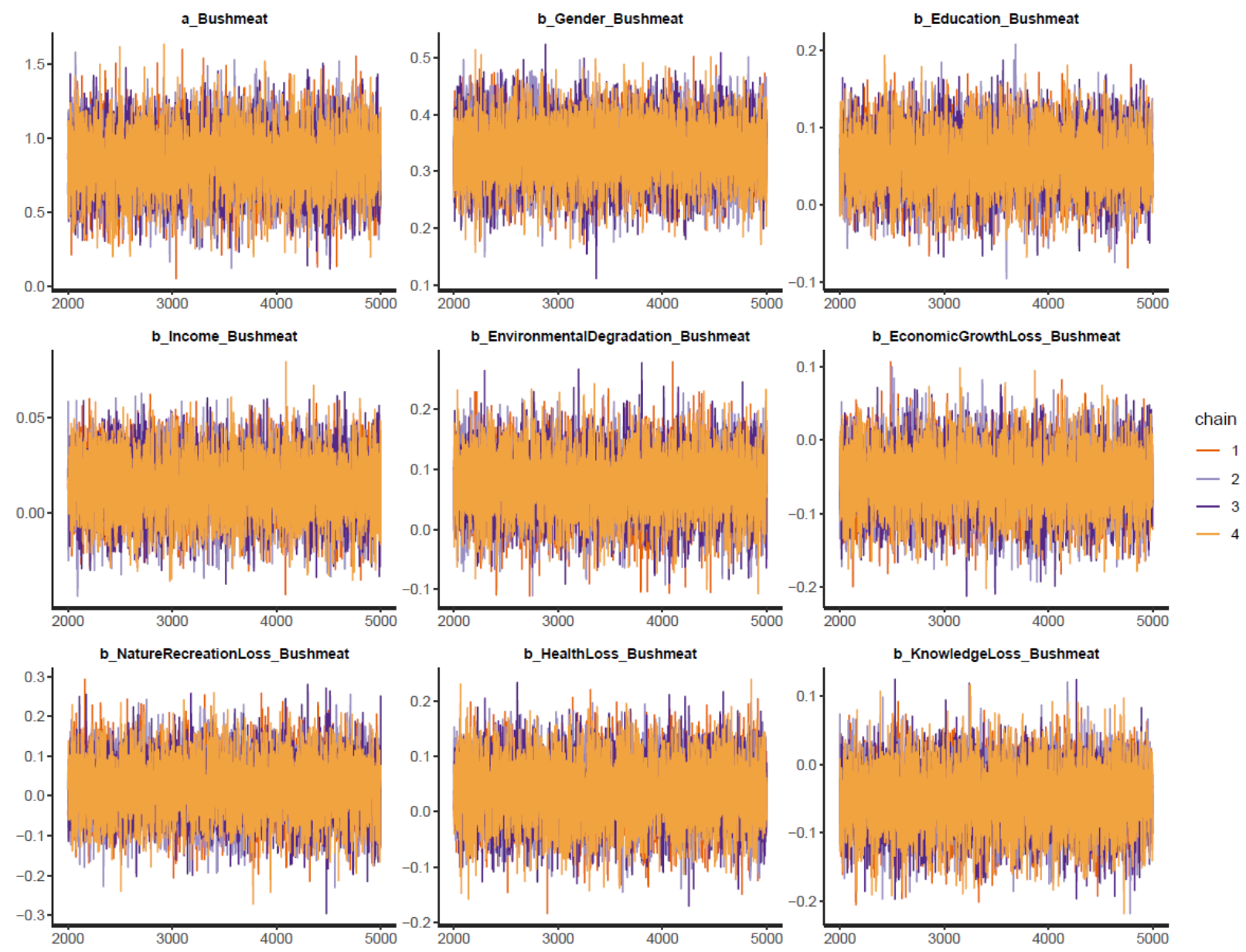

Figure 8: Model 2's trace plots with informative prior being normal distribution $(-1,0.5)$

The simulated results using informative priors being normal distribution $(-1,0.5)$ show that among five biodiversity loss perceptions, two perceptions $\left(\mu_{\text {EconomicGrowth }}=-0.06\right.$ and $\sigma_{\text {EconomicGrowth }}=0.04 ; \mu_{\text {KnowledgeLoss }}=-0.05$ and $\left.\sigma_{\text {Knowledgeloss }}=0.04\right)$ exhibit negative associations with the bushmeat consumption frequency as we postulated, whereas one perception ( $\mu_{\text {EnvironmentalDegradation }}=0.07$ and $\sigma_{\text {EnvironmentalDegradation }}=0.05$ ) exhibits a positive association, and the remaining two have ambiguous tendencies ( $\mu_{\text {HealthLoss }}=0.03$ and $\sigma_{\text {HealthLoss }}=0.05$; $\mu_{\text {NatureRecreationLoss }}=0.02$ and $\sigma_{\text {NatureRecreationLoss }}=0.07$ ) (see Table 3 ). The negative effects of EconomicGrowthLoss and KnowledgeLoss as well as the positive effect of EnvironmentalDegradation on urban residents' bushmeat consumption frequency are highly reliable since most of their probability distributions are located on one side of the $\mathrm{x}$-axis: left side for EconomicGrowthLoss and KnowledgeLoss and right side for EnvironmentalDegradation (see Figure 9A).

Table 2: Model 2's simulated posterior results 


\begin{tabular}{|c|c|c|c|c|c|c|c|c|}
\hline \multirow{2}{*}{ Parameters } & \multicolumn{4}{|c|}{$\begin{array}{c}\text { Informative priors } \\
\text { (belief on effect) }\end{array}$} & \multicolumn{4}{c|}{$\begin{array}{c}\text { Informative priors } \\
\text { (disbelief on effect) }\end{array}$} \\
\cline { 2 - 10 } & Mean & SD & n_eff & Rhat & Mean & SD & n_eff & Rhat \\
\hline Constant & 0.87 & 0.21 & 7956 & 1 & 0.84 & 0.21 & 7121 & 1 \\
\hline EnvironmentalDegradation & 0.07 & 0.05 & 10956 & 1 & 0.07 & 0.05 & 9221 & 1 \\
\hline EconomicGrowthLoss & -0.06 & 0.04 & 10633 & 1 & -0.05 & 0.04 & 10612 & 1 \\
\hline NatureRecreationLoss & 0.02 & 0.07 & 8421 & 1 & 0.02 & 0.07 & 8132 & 1 \\
\hline HealthLoss & 0.03 & 0.05 & 10653 & 1 & 0.03 & 0.05 & 9785 & 1 \\
\hline KnowledgeLoss & -0.05 & 0.04 & 11511 & 1 & -0.05 & 0.04 & 9732 & 1 \\
\hline Sex & 0.33 & 0.05 & 12062 & 1 & 0.33 & 0.05 & 10622 & 1 \\
\hline Education & 0.06 & 0.04 & 7541 & 1 & 0.06 & 0.04 & 7112 & 1 \\
\hline Income & 0.01 & 0.02 & 10362 & 1 & 0.01 & 0.02 & 9531 & 1 \\
\hline
\end{tabular}

Probability distributions Sex and Education demonstrate reliable positive association with the consumption behavior $\left(\mu_{\text {Sex }}=0.33\right.$ and $\sigma_{\text {Sex }}=0.05 ; \mu_{\text {Education }}=0.06$ and $\left.\sigma_{\text {Education }}=0.04\right)$. Specifically, male urban residents consume bushmeat more frequently than female ones; urban residents' educational level also predicts their more frequent consumption of bushmeat. People with high income are also found to consume bushmeat more frequently, but the prediction only has weak reliability because of its high standard deviation $\left(\mu_{\text {Sex }}=0.01\right.$ and $\left.\sigma_{\text {Sex }}=0.02\right)$.

These results remain almost similar when fitting Model 2 using informative priors being normal distribution $(0,0.5)$ (see Figures 9A and 9B), so Model 2's findings can be deemed robust.

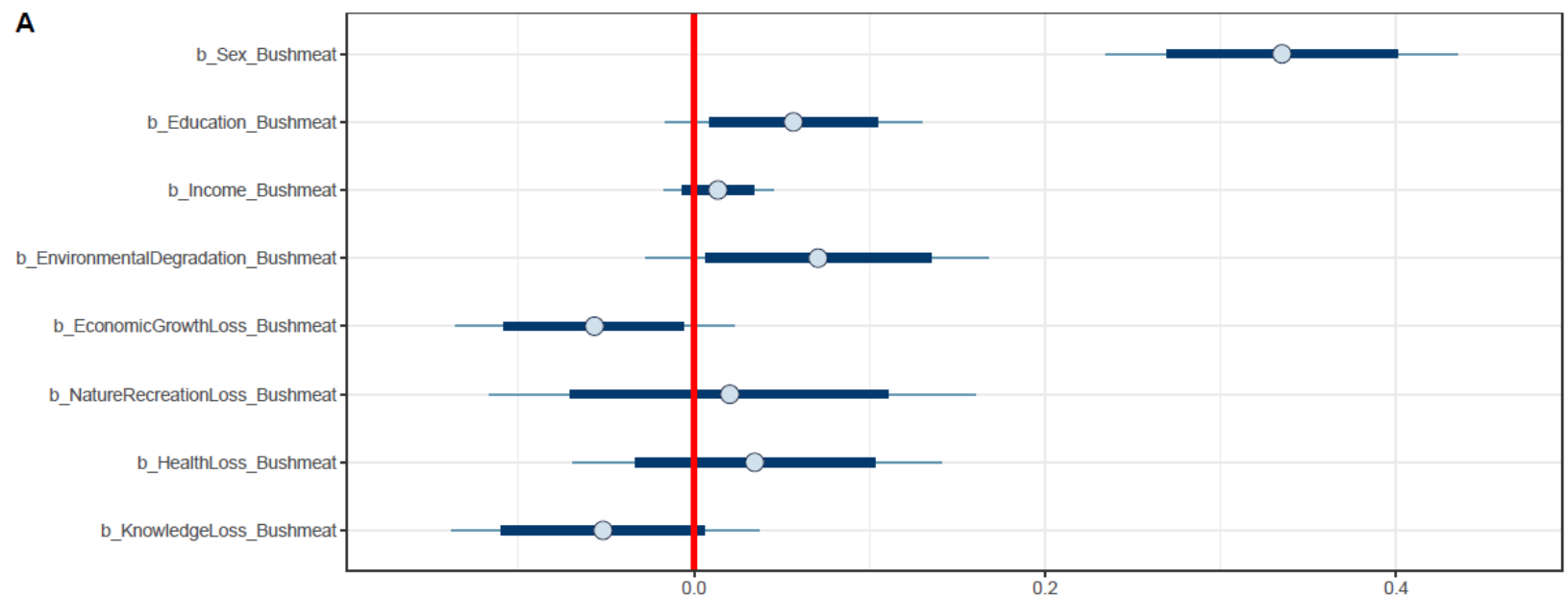

B

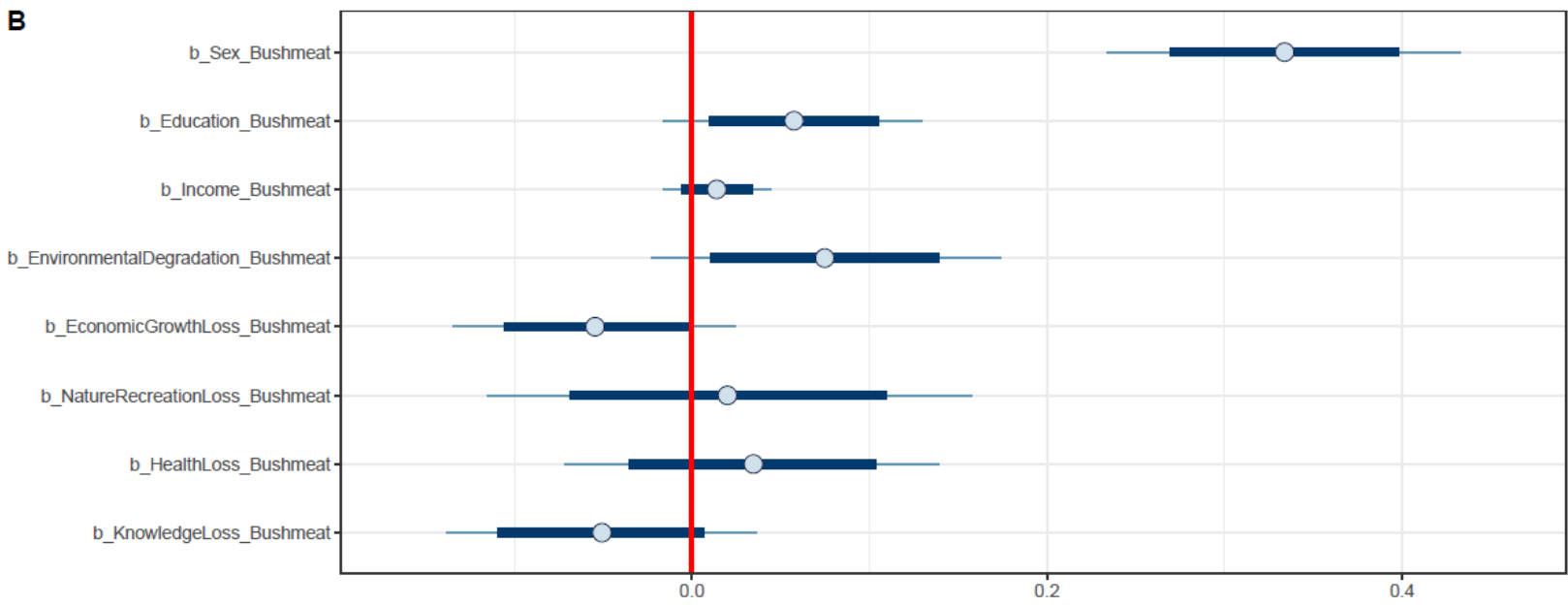


Figure 9: Model 2's interval plots of parameters' probability distributions. A - with informative prior being norm ($1,0.5), \mathbf{B}$ - with informative prior being normal distribution $(0,0.5)$

\section{Discussion}

The current study is one of the first research to examine the effects of urban residents' biodiversity loss perceptions on the support for the prohibition of illegal wildlife consumption and bushmeat consumption frequency. It employed the BMF on 535 Vietnamese urban residents for the investigation.

First of all, we found that all the perceptions about the negative impacts of biodiversity loss are positively associated with the attitude towards the preventive measure. In other words, urban residents who think that biodiversity loss negatively affects the environmental quality, economic growth, nature-based recreation opportunities, health, and knowledge are more likely to agree with the prohibition of illegal wildlife consumption. These results validate our assumption that subjective cost-benefit judgments influence an individual's attitude toward a subject. According to the Mindsponge mechanism, the cost-benefit judgements are made using previously accepted pieces of information into the mind; the closer those pieces are to the mindset, the more influences they have within the cost-benefit judgement process [41]. In this case, the distance can be proxied by the degree of agreement towards the information (or negative impacts of biodiversity loss).

The findings somewhat align with a recent study regarding Chinese public opinions on revising legislation and policy related to wildlife consumption and trade management. Due to the perceived threat of the Covid-19 outbreak, more than $90 \%$ of the respondents support more stringent policies and legislation on wildlife trade, consumption, and commercial exhibitions [59]. Shi et al. also note that the support is more prevalent among educated and urban people. In this case, the perceived risk of a pandemic can also be deemed a cost of biodiversity loss that drive Chinese urban people to support stringent policies and legislation.

Nevertheless, not all perceptions about the negative impacts of biodiversity loss could predict the reduced bushmeat consumption frequency. To elaborate, while people perceiving economic growth and knowledge losses as consequences of biodiversity loss consume bushmeat less frequently, people with other perceptions do not, or even consume more frequently. Particularly, people perceiving environmental degradation as a consequence of biodiversity loss tend to consume bushmeat more frequently. There are several explanations for such conflicting findings.

One of them is because of the high level of cultural additivity among Vietnamese urban people. According to Vuong, et al. [60], cultural additivity is "a mechanism whereby people of a given culture are willing to incorporate into their culture the values and norms from other systems of beliefs that might or might not logically contradict with principles of their existing system of beliefs." Due to the high level of resilience towards conflicting values induced by cultural additivity [61], Vietnamese urban residents can still consume bushmeat while being aware of the consequences of biodiversity loss and supporting the prohibition of illegal wildlife consumption. Although conflicting values with the mindset (or set of core cultural values) are often ejected, many types of information (or values), even conflicting ones, can exist simultaneously. That circumstance happens when the individual's multi-filtering system perceives both types of values to be beneficial. On the one hand, urban residents might consider supporting the prohibition of illegal wildlife consumption beneficial since it helps reduce biodiversity loss's consequences. On the other hand, eating bushmeat is still perceived to provide them with other types of benefits, like social status, prestige, nutritional value, health, or taste $[13,20]$.

It is noteworthy that people consuming bushmeat frequently and supporting the prohibition of illegal wildlife consumption tend to have similar characteristics: high income and educational level. The results seem to be paradoxical. However, as people with high income and education were identified as major bushmeat consumers $[13,20,28]$, they would be targeted by social marketing and demarketing campaigns, which encouraged them to support the prohibition of illegal wildlife consumption. Perhaps, they might not consider their consumed bushmeat to be "illegal." In any sense, this result again hints at the existing effect of cultural additivity on urban residents' perceptions and behaviors related to wildlife consumption. The paradox also exists in the wildlife tourism industry, where animal encounters are found to foster the connection to wildlife and pro-conservation behaviors [62,63]. Still, participation in such encounters is also strongly associated with increased wildlife consumption behaviors [64]. Cultural additivity 
can be a potential concept capitalized to understand such paradoxes, so further studies exploring this concept in wildlife consumption and tourism settings should be conducted.

If the cultural additivity really affects the existence of conflicting ideas within individuals' minds, policymakers and conservationists have to pay more attention to the effectiveness of social marketing and demarketing campaigns. In Vietnam's urban settings, for example, making residents realize the consequences of biodiversity loss on the economy and knowledge is useful to reduce bushmeat consumption frequency, while other consequences are not. In case those campaigns are insufficient for urban people to recognize the "cost" of bushmeat consumption, tougher measures (e.g. financial punishment) have to be put into perspective. Besides future studies regarding the effectiveness of social marketing campaigns, it is also essential to explore how social marketing and demarketing campaigns' contents (e.g. narratives, communication methods) affect the psychology and actual behaviors of the consumers.

Based on the current study's findings, the Mindsponge mechanism can supplement the explanation of the association between knowledge and public support for biodiversity conservation practices. Many studies have shown that increasing environmental knowledge can positively affect environmental attitudes and behaviors [34-36]. Still, Clayton, Prévot, Germain and Saint-Jalme [63] find that higher conservation knowledge cannot influence zoo visitors' environmental concerns and behavioral intent. Such distinction might result from the types of knowledge that are examined among those studies. Specifically, in Clayton et al.'s study, the conservation knowledge being asked does not make respondents relate to their subjective cost-benefit judgements; for example, "can you cite three endangered species?", "what are threats toward them?", etc.

The pieces of knowledge being asked in other studies, in contrast, are those that can be used as input for the costbenefit judgements of the respondents, such as questions related to the ecological system, pollution, greenhouse gases, population growth and urbanization, climate change, waste management, etc. [34-36]. Therefore, whether the respondents can relate conveyed knowledge to their subjective cost-benefit judgements towards a particular environmental (or biodiversity conservation) topic can be a critical factor affecting the impacts of environmental (or biodiversity conservation) knowledge on attitudes and behaviors. Future social marketing, demarketing, and educational campaigns are suggested to include the elements that help receivers relate to their cost-benefit judgements, which eventually drives them to build up an environmental-healing culture, or so-called the $11^{\text {th }}$ progressive cultural value [65]. One of the potential approaches is treating biodiversity and biodiversity loss following the ecologist's perspective during the social marketing, demarketing, and educational campaigns [66].

The contradicting predictions of biodiversity loss perceptions on the preventive measure attitude and consumption behavior highlight the limitation of the Mindsponge mechanism in examining the associations between ideations and behaviors. The translation from individuals' ideations to their actual behavior requires further theoretical research to expand the framework or provide a more transparent view of the transition between ideations and behaviors. Perhaps, individuals' behaviors result from complex information processing systems of multiple prioritized ideations in the mindset and receptive information from the external environment right before the behavior takes place. The objective of that process is to determine the behavior that is subjectively perceived to lead to the most beneficial outcome.

The study held some limitations, so they are explained here for transparency [67]. The sampling strategy of urban residents in Vietnam was not implemented in a random manner due to the prolonged social distancing for Covid-19 containment. However, applying Bayesian analysis, which helps provide precise estimations based on the data at hand, would facilitate later replicative studies and comparisons with findings analyzed using randomly collected data. Furthermore, the bushmeat consumption frequency employed as a dependent variable was quite ambiguous as the question was asked without a time frame. Usually, consumption frequency is referred to the frequency within the last month or two months. In our case, as the social distancing had been enacted for almost two months before the survey collection, it was plausible to think that urban residents rarely consumed any bushmeat during the last two months. As a result, we determined to ask the respondent using a general question: "How often do you eat bushmeat?" Given this ambiguity, the findings involved in bushmeat consumption frequency should be interpreted with caution. 
Supplementary
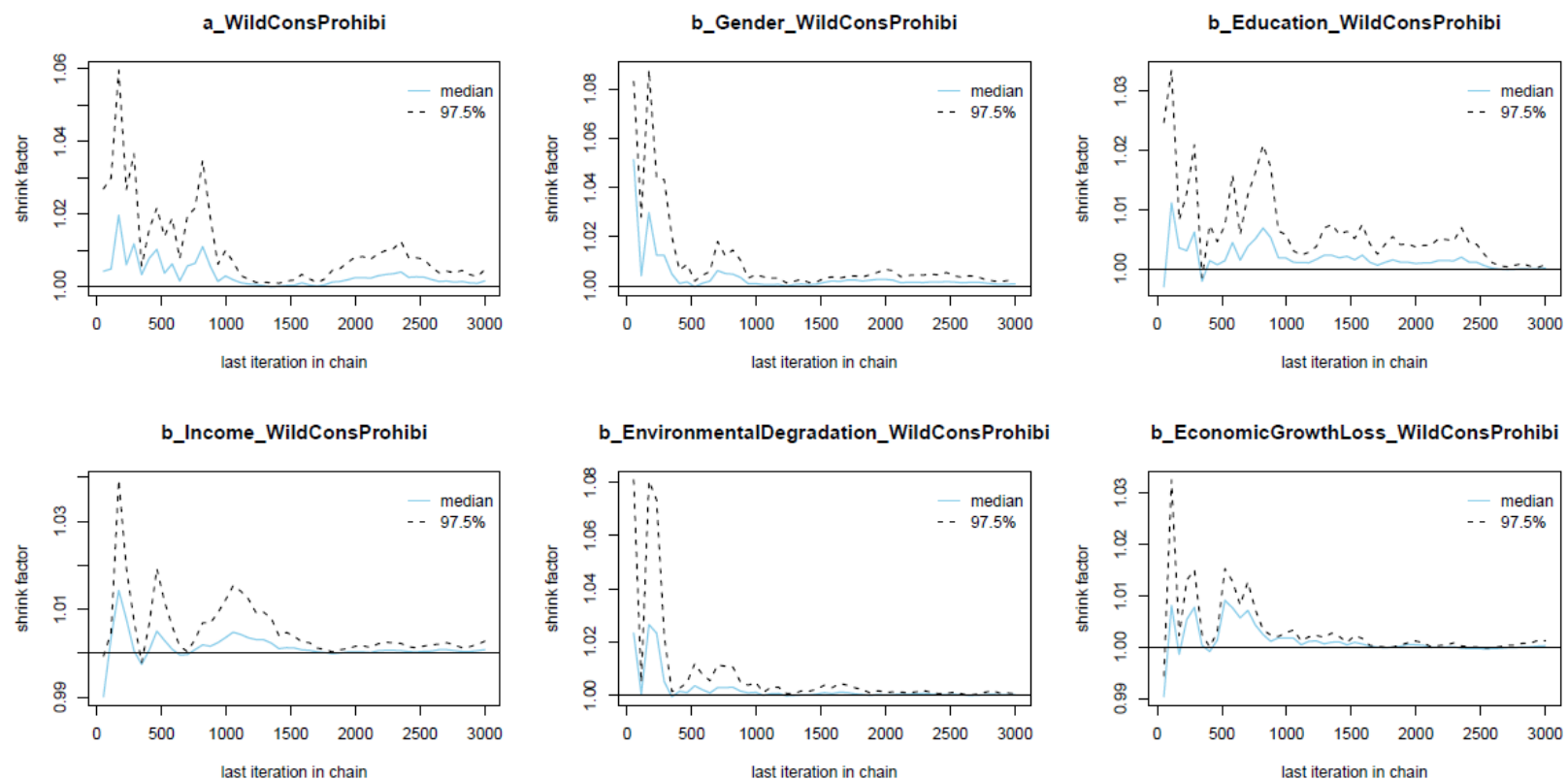

b_EnvironmentalDegradation_WildConsProhibi

b_EconomicGrowthLoss_WildConsProhibi
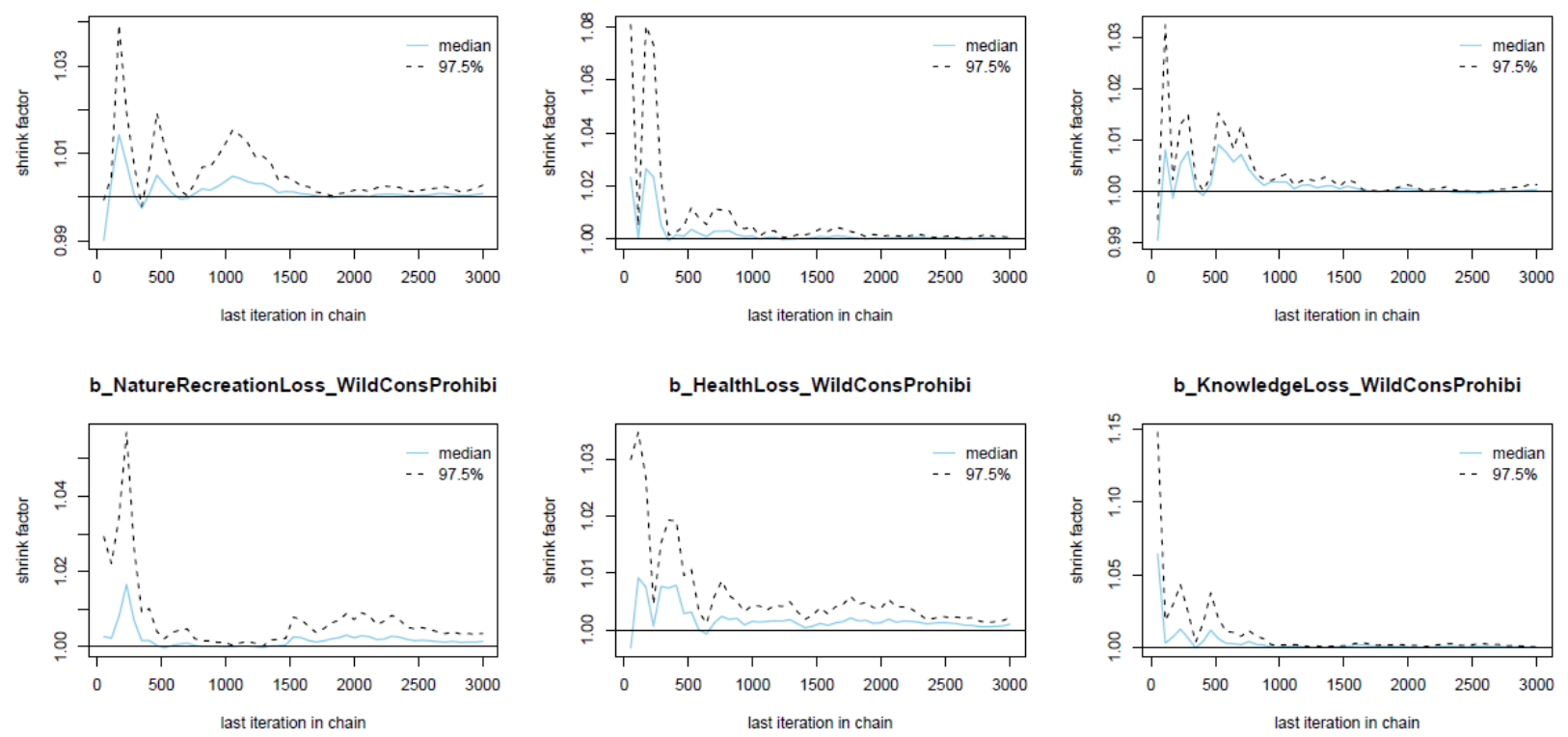

Figure S1: Model 1.b's Gelman plots 

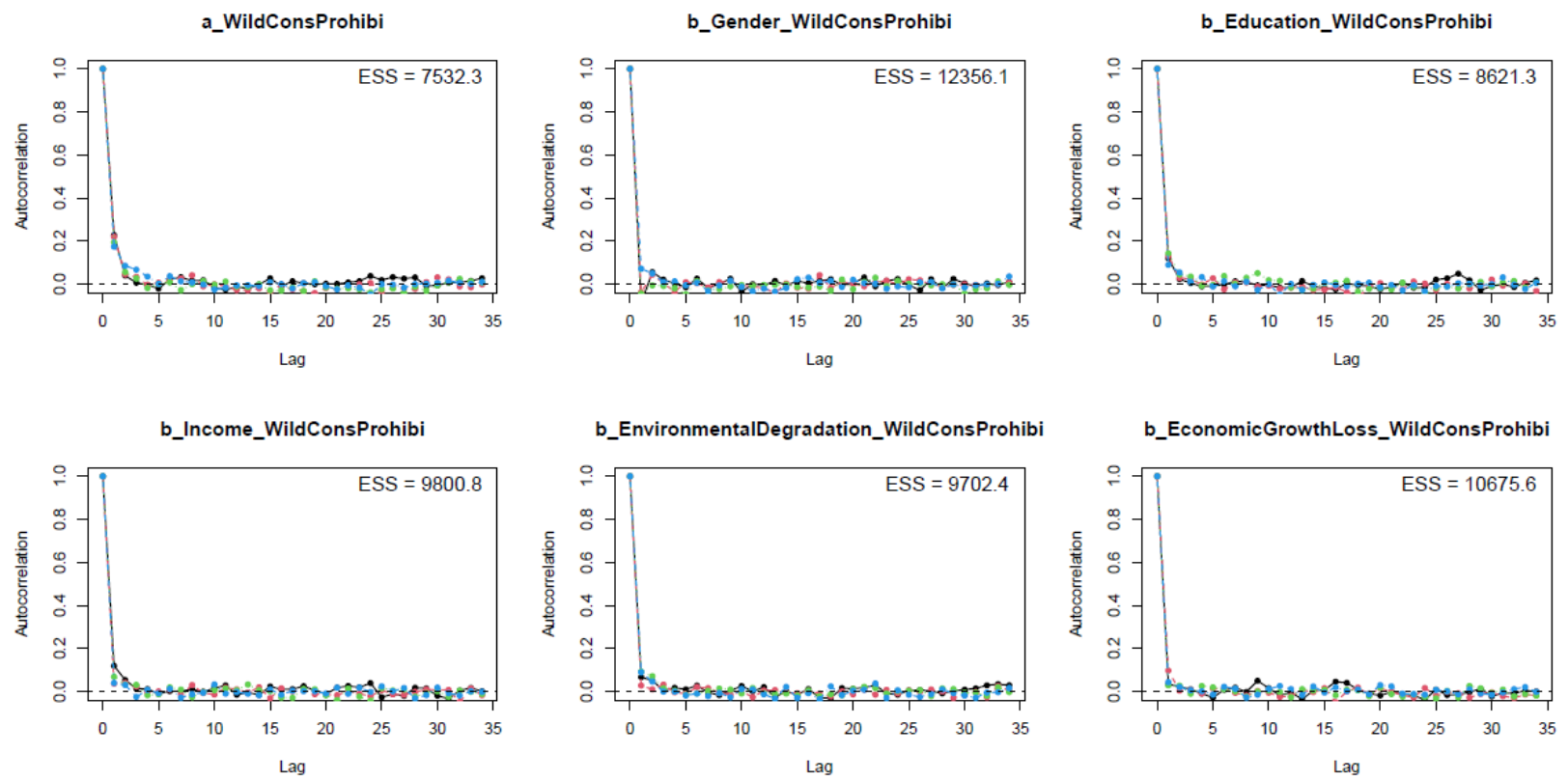

b_EconomicGrowthLoss_WildConsProhibi
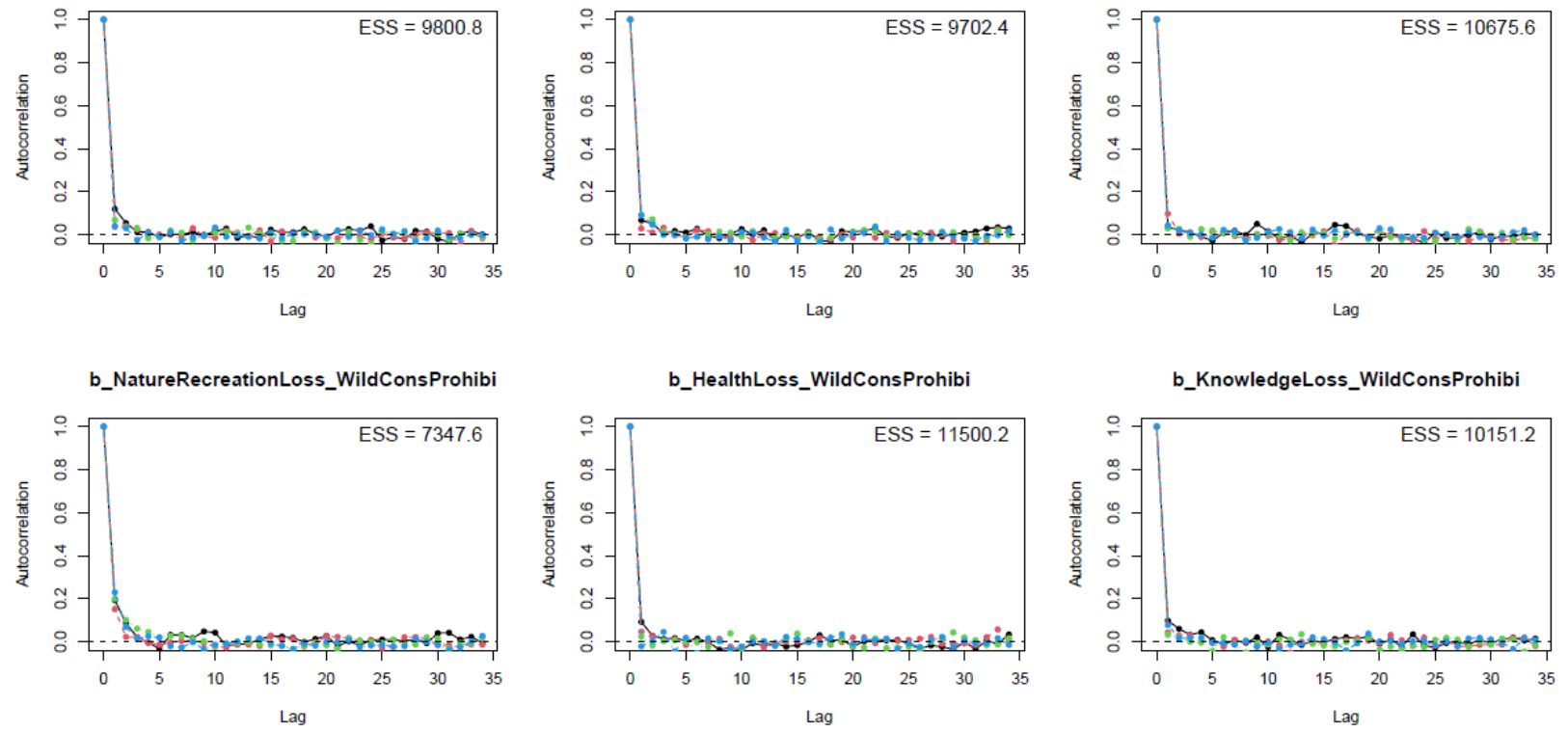

Figure S2: Model 1.b's autocorrelation plots 

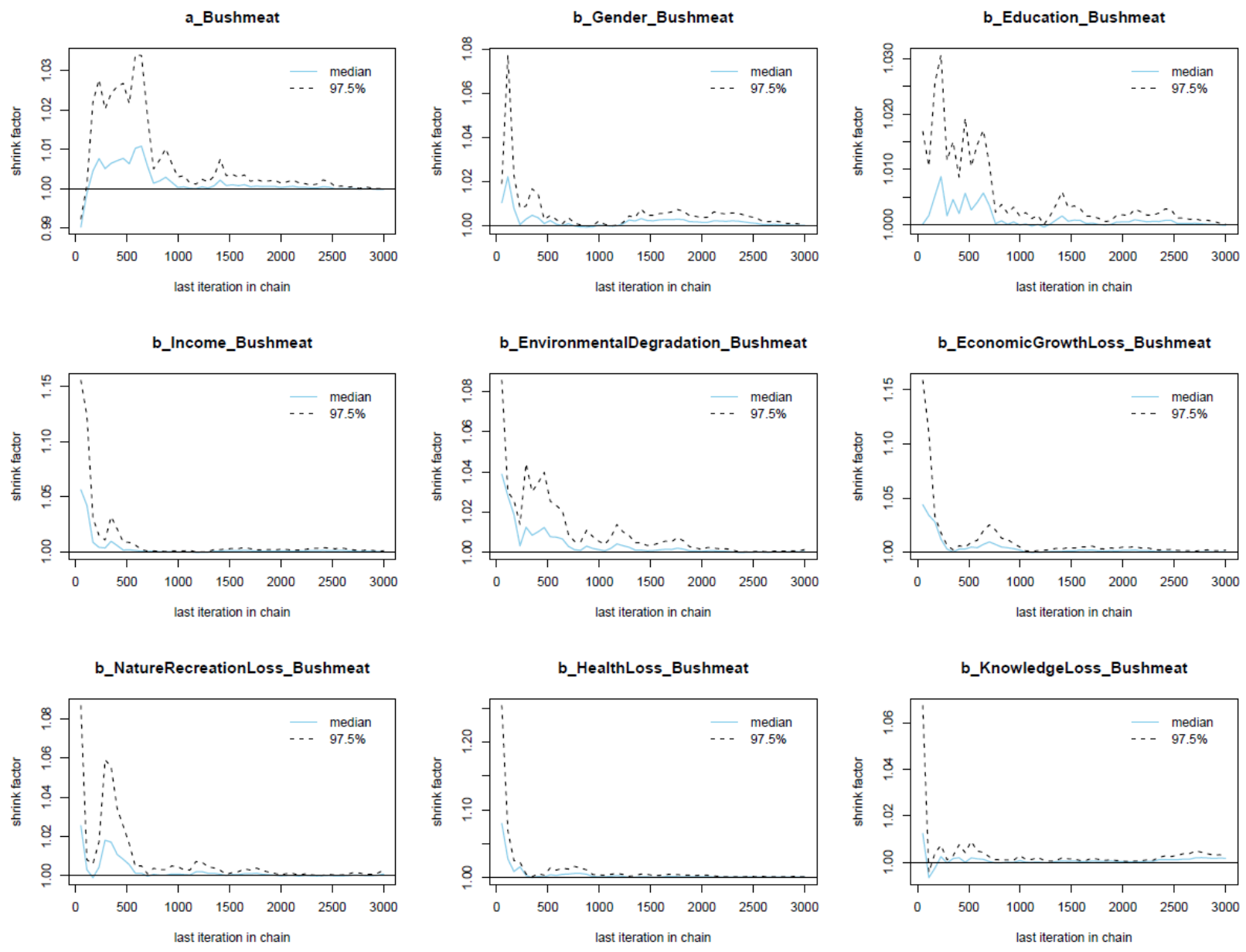

Figure S3: Model 2.b's Gelman plots 

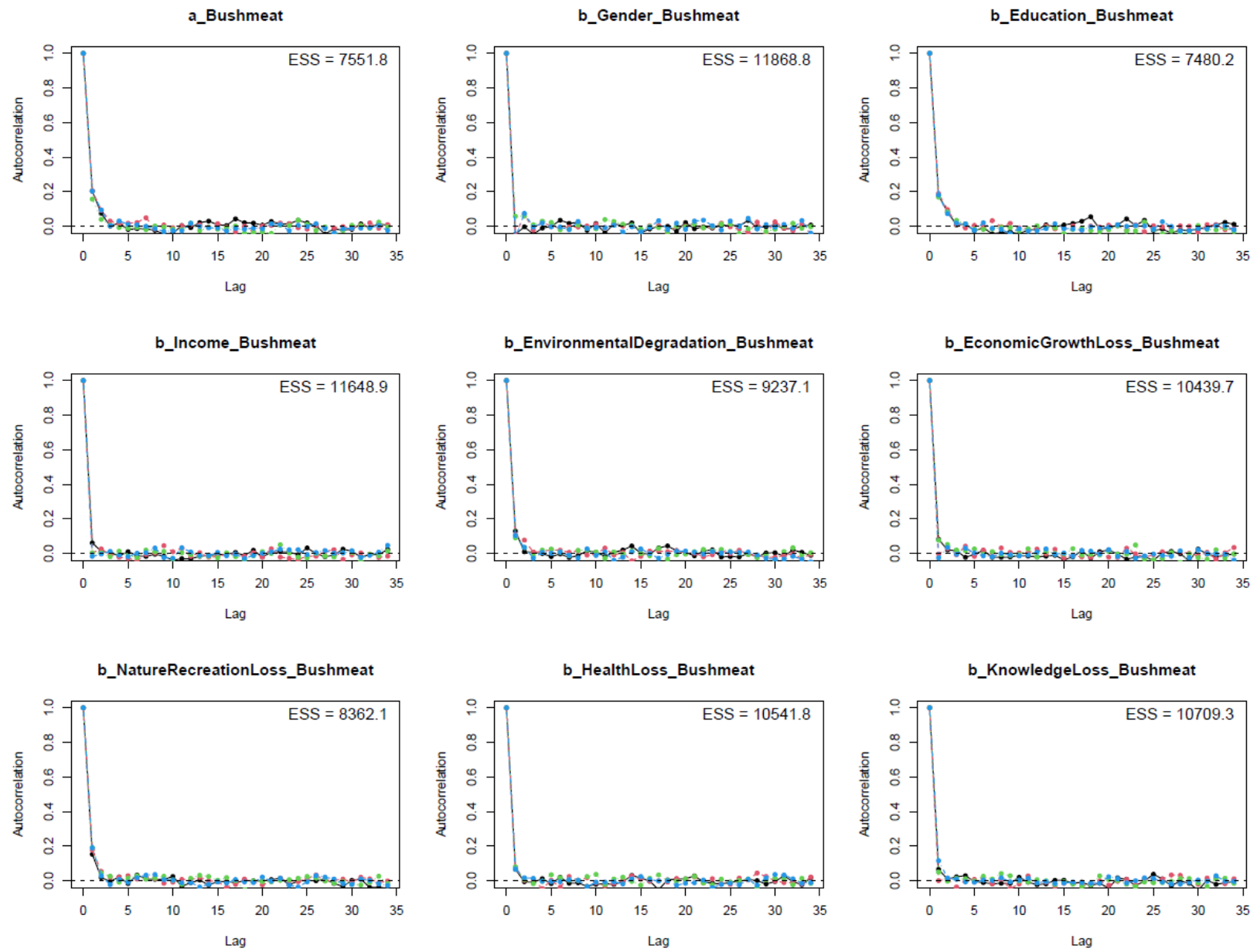

Figure S4: Model 2.b's autocorrelation plots

\section{References}

1. Van Dung, V.; Giao, P.M.; Chinh, N.N.; Tuoc, D.; Arctander, P.; MacKinnon, J. A new species of living bovid from Vietnam. Nature 1993, 363, 443-445.

2. Ministry of Natural Resources and Environment. Vietnam national biodiversity strategy to 2020, vision to 2030; Vietnamese government: Hanoi, 2014.

3. Lee, T.M.; Sigouin, A.; Pinedo-Vasquez, M.; Nasi, R. The harvest of wildlife for bushmeat and traditional medicine in East, South and Southeast Asia: Current knowledge base, challenges, opportunities and areas for future research; CIFOR: Bogor, Indonesia, 2014.

4. Fauna \& Flora International. Vietnam: Hotspot for primate diversity. Available online: https://www.fauna-flora.org/countries/vietnam (accessed on

5. Ministry of Natural Resources and Environment. Vietnam fifth national report to the United Nations Convention on Biologival Diversity; Vietnamese governments: Hanoi, 2014.

6. Brook, S.M.; Dudley, N.; Mahood, S.P.; Polet, G.; Williams, A.C.; Duckworth, J.; Van Ngoc, T.; Long, B. Lessons learned from the loss of a flagship: The extinction of the Javan rhinoceros Rhinoceros sondaicus annamiticus from Vietnam. Biological Conservation 2014, 174, 21-29. 
7. Dang, H.H.; Dang, H.P. Profits, management and the control over illegal wildlife trade in Vietnam. In Proceedings of the National Conference of Prevention and Combat the Offence Against Wildlife, Biodiversity and Natural Preservation, Hanoi, Vienam, 20210; pp. 13-20.

8. Ngoc, A.C.; Wyatt, T. A green criminological exploration of illegal wildlife trade in Vietnam. Asian Journal of Criminology 2013, 8, 129-142.

9. Van Song, N. Wildlife trading in Vietnam: situation, causes, and solutions. The Journal of Environment and Development 2008, 17, 145-165.

10. Phan, V.K. Decree No. 32/2006/ND-CP: On management of endangered, precious, and rare forest plants and animals. 2006.

11. Nguyen, T.D. Decree No. 82/2006/ND-CP: On management of export, import, re-export, introduction from the sea, transit, breeding, rearing and artificial propagation of endangered species of precious and rare wild fauna and flora. 2006.

12. Nguyen, X.P. Decree No. 35/2019/ND-CP: Penalties for administrative violations against regulations on forestry. 2019.

13. Shairp, R.; Veríssimo, D.; Fraser, I.; Challender, D.; MacMillan, D. Understanding urban demand for wild meat in Vietnam: implications for conservation actions. PloS One 2016, 11, e0134787, doi:10.1371/journal.pone.0134787.

14. Bui, H.T.; Pham, L.H.; Jones, T.E. Governance and Management of Protected Areas in Vietnam: Nature-Based Tourism in Mountain Areas. In Nature-Based Tourism in Asia's Mountainous Protected Areas: A Trans-regional Review of Peaks and Parks, Jones, T.E., Bui, H.T., Apollo, M., Eds.; Springer: Cham, Switzerland, 2021; pp. 173-195.

15. Challender, D.W.; MacMillan, D.C. Poaching is more than an enforcement problem. Conservation Letters 2014, 7, 484-494, doi:10.1111/conl.12082.

16. Ngoc, T. Alarming problems of wildlife trade. Available online: https://congan.com.vn/vuan/phong-su/bao-dong-nan-buon-ban-dong-vat-hoang-da 102668.html (accessed on

17. !!! INVALID CITATION !!! \{\}.

18. Drury, R. Reducing urban demand for wild animals in Vietnam: examining the potential of wildlife farming as a conservation tool. Conservation Letters 2009, 2, 263-270.

19. Tensen, L. Under what circumstances can wildlife farming benefit species conservation? Global Ecology and Conservation 2016, 6, 286-298.

20. Drury, R. Hungry for success: urban consumer demand for wild animal products in Vietnam. Conservation and Society 2011, 9, 247-257, doi:10.4103/0972-4923.86995.

21. Veríssimo, D.; Challender, D.W.; Nijman, V. Wildlife trade in Asia: start with the consumer. Asian Journal of Conservation Biology 2012, 1, 49-50.

22. Biggs, D.; Courchamp, F.; Martin, R.; Possingham, H.P. Legal trade of Africa's rhino horns. Science 2013, 339, 1038-1039.

23. Olmedo, A.; Veríssimo, D.; Challender, D.W.; Dao, H.T.T.; Milner-Gulland, E. Who eats wild meat? Profiling consumers in Ho Chi Minh City, Vietnam. People and Nature 2021, 3, 700-710.

24. Veríssimo, D.; Vieira, S.; Monteiro, D.; Hancock, J.; Nuno, A. Audience research as a cornerstone of demand management interventions for illegal wildlife products: Demarketing sea turtle meat and eggs. Conservation Science and Practice 2020, 2, e164.

25. Nguyen, X.P. Directive No. 29/CT-TTh: On urgent solutions for wildlife managemet. 2020.

26. Bennett, N.J.; Roth, R.; Klain, S.C.; Chan, K.; Christie, P.; Clark, D.A.; Cullman, G.; Curran, D.; Durbin, T.J.; Epstein, G. Conservation social science: Understanding and integrating human dimensions to improve conservation. Biological Conservation 2017, 205, 93-108.

27. Bennett, N.J.; Roth, R.; Klain, S.C.; Chan, K.M.; Clark, D.A.; Cullman, G.; Epstein, G.; Nelson, M.P.; Stedman, R.; Teel, T.L. Mainstreaming the social sciences in conservation. Conservation Biology 2017, 31, 56-66. 
28. Sandalj, M.; Treydte, A.C.; Ziegler, S. Is wild meat luxury? Quantifying wild meat demand and availability in Hue, Vietnam. Biological Conservation 2016, 194, 105-112.

29. Vuong, Q.-H.; Bui, Q.-K.; La, V.-P.; Vuong, T.-T.; Nguyen, V.-H.T.; Ho, M.-T.; Nguyen, H.-K.T.; Ho, M.-T. Cultural additivity: behavioural insights from the interaction of Confucianism, Buddhism and Taoism in folktales. Palgrave Communications 2018, 4, 1-15.

30. Hwang, K.-K.; Han, K.-H. Face and morality in Confucian society. In Oxford Handbook of Chinese Psychology, Bond, M.H., Ed.; Oxford University Press: Oxford, UK, 2010.

31. Wright, L.T.; Nancarrow, C.; Kwok, P.M. Food taste preferences and cultural influences on consumption. British Food Journal 2001.

32. Amoah, A.; Addoah, T. Does environmental knowledge drive pro-environmental behaviour in developing countries? Evidence from households in Ghana. Environment, Development and Sustainability 2021, 23, 2719-2738.

33. Liu, P.; Teng, M.; Han, C. How does environmental knowledge translate into pro-environmental behaviors?: The mediating role of environmental attitudes and behavioral intentions. Science of the Total Environment 2020, 728, 138126.

34. Polonsky, M.J.; Vocino, A.; Grau, S.L.; Garma, R.; Ferdous, A.S. The impact of general and carbonrelated environmental knowledge on attitudes and behaviour of US consumers. Journal of Marketing Management 2012, 28, 238-263.

35. Faize, F.A.; Akhtar, M. Addressing environmental knowledge and environmental attitude in undergraduate students through scientific argumentation. Journal of Cleaner Production 2020, 252, 119928.

36. Bradley, J.C.; Waliczek, T.M.; Zajicek, J.M. Relationship between environmental knowledge and environmental attitude of high school students. The Journal of Environmental Education 1999, $30,17-21$.

37. Nguyen, M.-H. Multifaceted interactions between urban humans and biodiversity-related concepts: A developing-country dataset. Data Intelligence 2021, 3, 578-605.

38. Kim, Y.; Dykema, J.; Stevenson, J.; Black, P.; Moberg, D.P. Straightlining: overview of measurement, comparison of indicators, and effects in mail-web mixed-mode surveys. Social Science Computer Review 2019, 37, 214-233.

39. Taber, K.S. The use of Cronbach's alpha when developing and reporting research instruments in science education. Research in Science Education 2018, 48, 1273-1296.

40. Jones, T.E.; Nguyen, M.-H. Nature-Based Tourism Motivations and Visit Profiles of Domestic and International Segments to a Japanese National Park. Quaestiones Geographicae 2021, 40, 77-92.

41. Nguyen, M.-H.; Le, T.-T.; Ho, M.-T.; Nguyen, H.T.T.; Vuong, Q.-H. Alice in Suicideland: Exploring the Suicidal Ideation Mechanism through the Sense of Connectedness and Help-Seeking Behaviors. IJERPH 2021, 18, 3681, doi:https://doi.org/10.3390/ijerph18073681.

42. Vuong, Q.-H.; Napier, N.K. Acculturation and global mindsponge: an emerging market perspective. International Journal of Intercultural Relations 2015, 49, 354-367.

43. Vuong, Q.-H. Global Mindset as the Integration of Emerging Socio-Cultural Values Through Mindsponge Processes: A Transition Economy Perspective. In Global Mindsets: Exploration and Perspectives, Kuada, J., Ed.; Routledge: 2016; pp. 109-126.

44. Vuong, Q.-H.; Nguyen, M.-H.; Le, T.-T. A mindsponge-based investigation into the psychoreligious mechanism behind suicide attacks; De Gruyter / Sciendo: Warsaw, Poland, 2021.

45. McElreath, R. Statistical rethinking: A Bayesian course with examples in R and Stan; Chapman and Hall/CRC Press: Boca Raton, London, New York, 2018.

46. Wagenmakers, E.-J.; Marsman, M.; Jamil, T.; Ly, A.; Verhagen, J.; Love, J.; Selker, R.; Gronau, Q.F.; Šmíra, M.; Epskamp, S. Bayesian inference for psychology. Part I: Theoretical advantages and practical ramifications. Psychonomic bulletin review 2018, 25, 35-57. 
47. Block, J.H.; Wagner, M.J.B.S.; Environment, t. The effect of family ownership on different dimensions of corporate social responsibility: Evidence from large US firms. Business Strategy and the Environment 2014, 23, 475-492.

48. Hahn, E.D.; Doh, J.P. Using Bayesian methods in strategy research: an extension of Hansenet al. Strategic Management Journal 2006, 27, 783-798.

49. Western, B.; Jackman, S. Bayesian inference for comparative research. American Political Science Review 1994, 88, 412-423.

50. Khatibisepehr, S.; Huang, B.; Khare, S. Design of inferential sensors in the process industry: A review of Bayesian methods. Journal of Process Control 2013, 23, 1575-1596.

51. Leamer, E.E.J.T.r.o.e.; statistics. Multicollinearity: a Bayesian interpretation. The Review of Economics and Statistics 1973, 55, 371-380.

52. Adepoju, A.A.; Ojo, O.O. Bayesian method for solving the problem of multicollinearity in regression. Afrika Statistika 2018, 13, 1823-1834.

53. Jaya, I.; Tantular, B.; Andriyana, Y. A Bayesian approach on multicollinearity problem with an Informative Prior. In Proceedings of the Journal of Physics: Conference Series, 2019; p. 012021.

54. Vuong, Q.H.; Ho, M.-T.; Nguyen, M.-H.; Thang Hang, P.; Vuong, T.-T.; Khuc, Q.; Ho, H.-A.; La, V.-P. On the environment-destructive probabilistic trends: a perceptual and behavioral study on video game players. Technology in Society 2021, 65, 101530, doi:10.1016/j.techsoc.2021.101530.

55. Vehtari, A.; Gabry, J. Bayesian Stacking and Pseudo-BMA weights using the loo package, loo 2.2.0; 2019.

56. Vuong, Q.-H.; La, V.-P.; Nguyen, M.-H.; Ho, M.-T.; Tran, T.; Ho, M.-T. Bayesian analysis for social data: A step-by-step protocol and interpretation. MethodsX 2020, 7, 100924, doi:10.1016/j.mex.2020.100924.

57. Vuong, Q.-H.; La, V.-P.; Nguyen, M.-H.; Ho, M.-T.; Ho, M.-T.; Mantello, P. Improving Bayesian statistics understanding in the age of Big Data with the bayesvl R package. Software Impacts 2020, 4, 100016, doi:10.1016/j.simpa.2020.100016.

58. La, V.-P.; Vuong, Q.-H. bayesvl: Visually learning the graphical structure of Bayesian networks and performing MCMC with'Stan'. The Comprehensive R Archive Network (CRAN) 2019.

59. Shi, X.; Zhang, X.; Xiao, L.; Li, B.V.; Liu, J.; Yang, F.; Zhao, X.; Cheng, C.; Lü, Z. Public perception of wildlife consumption and trade during the COVID-19 outbreak. Biodiversity Science 2020, 28, 630.

60. Vuong, Q.-H.; Bui, Q.-K.; La, V.-P.; Vuong, T.-T.; Nguyen, V.-H.T.; Ho, M.-T.; Nguyen, H.-K.T.; Ho, M.-T. Cultural additivity: behavioural insights from the interaction of Confucianism, Buddhism and Taoism in folktales. Palgrave Communications 2018, 4, 143, doi:10.1057/s41599-018-01892.

61. Small, S.; Blanc, J. Mental health during COVID-19: Tam Giao and Vietnam's response. Frontiers in Psychiatry 2020, 11.

62. Skibins, J.C.; Powell, R.B. Conservation caring: Measuring the influence of zoo visitors' connection to wildlife on pro-conservation behaviors. Zoo Biology 2013, 32, 528-540.

63. Clayton, S.; Prévot, A.C.; Germain, L.; Saint-Jalme, M. Public support for biodiversity after a zoo visit: Environmental concern, conservation knowledge, and self-efficacy. Curator: The Museum Journal 2017, 60, 87-100.

64. Rizzolo, J.B. Wildlife tourism and consumption. Journal of Sustainable Tourism 2021, In Press, 114.

65. Vuong, Q.H. The semiconducting principle of monetary and environmental values exchange. Economics and Business Letters 2021, 10, 284-290, doi:10.17811/ebl.10.3.2021.284-290.

66. Mace, G.M.; Norris, K.; Fitter, A.H. Biodiversity and ecosystem services: a multilayered relationship. Trends in Ecology \& Evolution 2012, 27, 19-26. 
67. Vuong, Q.-H. Reform retractions to make them more transparent. Nature 2020, 582, 149, doi:10.1038/d41586-020-01694-x. 